\title{
Relaxin remodels fibrotic healing following myocardial infarction
}

\author{
Chrishan S Samuel ${ }^{1,2}$, Sofia Cendrawan ${ }^{1,2}$, Xiao-Ming Gao ${ }^{3}$, Ziqiu Ming ${ }^{3}$, Chongxin Zhao ${ }^{1}$, Helen Kiriazis ${ }^{3}$, \\ Qi $\mathrm{Xu}^{3}$, Geoffrey W Tregear ${ }^{1,2}$, Ross AD Bathgate ${ }^{1,2}$ and Xiao-Jun $\mathrm{Du}^{3}$
}

In the setting of myocardial infarction (MI), implanted stem cell viability is low and scar formation limits stem cell homing, viability, and integration. Thus, interventions that favorably remodel fibrotic healing may benefit stem cell therapies. However, it remains unclear whether it is feasible and safe to remodel fibrotic healing post-MI without compromising ventricular remodeling and dysfunction. This study, therefore, determined the anti-fibrotic and other effects of the hormone, relaxin in a mouse model of Ml. Adult male mice underwent left coronary artery ligation-induced $\mathrm{Ml}$ and were immediately treated with recombinant human relaxin $(\mathrm{MI}+\mathrm{RLX})$ or vehicle $(\mathrm{MI}+\mathrm{VEH})$ over 7 or 30 days, representing time points of early and mature fibrotic healing. Cardiac function was assessed by echocardiography and catheterization, while comprehensive immunohistochemistry, morphometry, and western blotting were performed to explore the relaxin-induced mechanisms of action post-MI. RLX significantly inhibited the MI-induced progression of cardiac fibrosis over 7 and 30 days, which was associated with a reduction in TGF- $\beta 1$ expression, myofibroblast differentiation, and cardiomyocyte apoptosis in addition to a promotion of matrix metalloproteinase- 13 levels and de novo blood vessel growth (all $P<0.05$ vs respective measurements from $\mathrm{MI}+\mathrm{VEH}$ mice). Despite the evident fibrotic healing post-MI, relaxin did not adversely affect the incidence of ventricular free-wall rupture or the extent of LV remodeling and dysfunction. These combined findings demonstrate that RLX favorably remodels the process of fibrotic healing post-infarction by lowering the density of mature scar tissue in the infarcted myocardium, border zone, and non-infarcted myocardium, and may, therefore, facilitate cell-based therapies in the setting of ischemic heart disease.

Laboratory Investigation (2011) 91, 675-690; doi:10.1038/labinvest.2010.198; published online 10 January 2011

KEYWORDS: angiogenesis; apoptosis; cardiac fibrosis; relaxin; remodeling; TGF- $\beta 1$

Ischemic heart disease constitutes the leading cause of morbidity and mortality in the world. Following myocardial infarction (MI), reparative fibrotic healing occurs in the infarct region (IR) to maintain structural integrity, denoting an irreversible loss of tissue function while preventing myocardial regeneration. ${ }^{1-3}$ Reactive fibrosis occurs in the non-infarcted myocardium in response to biomechanical and/or hormonal stimulation, contributing to increased myocardial stiffness and global dysfunction. Hence, interventions targeting excessive fibrosis as a result of MI are of major therapeutic importance. $^{1}$

Despite its significance, the regulation of cardiac fibrosis, especially in the reparative form, is poorly understood. While current anti-fibrotic treatments have been effective in improving the outcomes of hypertensive heart disease, the efficacy of these therapies on other types of heart disease has been much less studied. ${ }^{1,3,4}$ Alternatively, stem cell based therapies have been hampered by the low survival rate of implanted stem cells in addition to scar formation limiting stem cell homing, proliferation, and overall viability, ${ }^{5}$ while forming a barrier against the proper integration of implanted stem cells and native cardiomyocytes. Thus, interventions that favorably remodel fibrotic healing may benefit stem cell based therapies in the setting of MI. However, the feasibility and safety of remodeling reparative healing following $\mathrm{MI}$ remains unclear, and the potential risk of worsening the development of post-MI ventricular wall rupture or LV remodeling and associated dysfunction must be considered.

\footnotetext{
${ }^{1}$ Howard Florey Institute, University of Melbourne, Parkville, Victoria, Australia; ${ }^{2}$ Department of Biochemistry and Molecular Biology, University of Melbourne, Parkville, Victoria, Australia and ${ }^{3}$ Baker IDI Heart and Diabetes Institute, Central Medical School, Monash University, Melbourne, Victoria, Australia

Correspondence: Dr CS Samuel, PhD, Howard Florey Institute and Department of Biochemistry and Molecular Biology, University of Melbourne, Parkville, Victoria 3010, Australia or Dr X-J Du, MD, PhD, Baker IDI Heart and Diabetes Institute, Central Medical School, Monash University, 75 Commercial Road, Melbourne, Victoria 3004, Australia.
}

E-mail: chrishan.samuel@florey.edu.au or xiaojun.du@ bakeridi.edu.au

Received 3 May 2010; revised 1 November 2010; accepted 17 November 2010 
Only if deemed feasible and safe can strategies that directly target collagen turnover and organization offer the greatest potential benefits and improve myocardial regeneration by stem cell based therapies in the setting of MI.

The naturally occurring hormone, relaxin, is emerging as a potent anti-fibrotic therapy with rapid-occurring efficacy, based on its ability to inhibit pro-fibrotic factor-stimulated myofibroblast differentiation and collagen production (fibrogenesis), while promoting matrix metalloproteinase (MMP)induced collagen degradation in vivo. ${ }^{6-10}$ Relaxin has been shown to inhibit the collagen-promoting actions of transforming growth factor- $\beta 1$ (TGF- $\beta 1$ ) and angiotensin II in rat cardiac fibroblasts, ${ }^{11}$ and was more recently shown to inhibit TGF- $\beta 1$ signaling through stimulation of the nitric oxide (NO) pathway to inhibit Smad2 phosphorylation. ${ }^{12}$ Of further significance are the findings that relaxin also stimulates vasodilation and coronary flow via NO signaling, increases angiogenesis by upregulating vascular endothelial growth factor and basic fibroblast growth factor ${ }^{6-8,13-15}$ and inhibits cardiomyocyte apoptosis by altering the $\mathrm{Bcl} 2 / \mathrm{Bax}$ ratio; ${ }^{16}$ promoting its therapeutic potential.

The aim of this study was to determine if relaxin could effectively influence post-infarct fibrotic healing (based on its known actions) and act as a safe and viable complementary agent for cardiac stem cell based therapies. To achieve this, comprehensive histological and morphometric analyses of the anti-fibrotic and other effects of relaxin were evaluated in various regions of the infarcted mouse heart, following MI, and cardiac functional assessment conducted by echocardiography and micromanometry. Particular attention was given to evaluating the potential risk of relaxin therapy on the extent of ventricular remodeling, dysfunction, and ventricular wall rupture.

\section{MATERIALS AND METHODS Materials}

Recombinant human gene-2 (H2) relaxin was generously provided by Corthera Inc. (San Mateo, CA, USA) and is bioactive in mice. ${ }^{11}$

\section{Animals and Experimental Protocol}

All outlined procedures were approved by a local Animal Ethics Committee, which adheres to the Australian Code of Practice for the care and use of animals for scientific purposes, and conformed with the Guide for the Care and Use of Laboratory Animals published by the US National Institutes of Health. The 20-week-old male C57Bl/6J mice used in this study were housed and fed in a controlled environment and underwent open-chest surgery under anesthesia to induce left coronary artery occlusion $(n=145)$ or sham operation (where animals were subjected to the same procedures except for occlusion of the coronary artery; $n=26$ ), as described in detail previously. ${ }^{17}$ To address the impact of IS on the MIinduced complications and responses to relaxin therapy, the ligation level of the coronary was varied to induce a moderate
(IS $<35 \%$ ) or large (IS $>35 \%$ ) IS. Immediately after chest closure, animals were subdivided into four groups: those receiving vehicle $(20 \mathrm{mM}$ sodium acetate buffer, $\mathrm{pH}$ 5.0; $\mathrm{MI}+\mathrm{VEH} ; n=37)$ or $\mathrm{H} 2$ relaxin $(0.5 \mathrm{mg} / \mathrm{kg} /$ day $)$ in vehicle $(\mathrm{MI}+\mathrm{RLX} ; n=41)$ for a 7 -day period and those receiving vehicle $(n=31)$ or $\mathrm{H} 2$ relaxin $(n=36)$ for a 30 -day period. A small skin incision was made on the dorsal surface of mice subjected to coronary artery occlusion and a subcutaneous pouch was made by blunt dissection for the implantation of osmotic mini-pumps (model 2001 for 7 days; model 2004 for 30 days; Alzet, Cupertino, CA, USA) containing vehicle or $0.5 \mathrm{mg} / \mathrm{kg} /$ day $\mathrm{H} 2$ relaxin, before animals were allowed to recover. Sham-operated mice were also separated to control for the day $7(n=17)$ and day $30(n=9)$ treatment groups. The dose of $\mathrm{H} 2$ relaxin used had previously been shown to successfully prevent and/or reverse fibrosis progression in several other experimental models of heart disease, ${ }^{6,10,11,18}$ and produce $20-40 \mathrm{ng} / \mathrm{ml}$ of circulating $\mathrm{H} 2$ relaxin in rodents. ${ }^{19,20}$ The effects of $\mathrm{H} 2$ relaxin alone on sham-operated animals was not assessed based on previous studies consistently demonstrating that relaxin does not affect basal collagen turnover. ${ }^{6,10,11}$ The time points chosen were based on a subacute phase of MI, when scar tissue begins to form in the infarct region (IR) of the myocardium, but the noninfarct region (NIR) remains unaffected (day 7), and when the heart undergoes chronic MI (day 30).

\section{Cardiac Function Assessment and Tissue Collection}

One day prior to animal sacrifice (on days 6 and 29, respectively), transthoracic echocardiography was performed on anesthetized mice, using a Sonos 5500 ultrasound machine (Hewlett Packard), as described previously. ${ }^{17,21}$ Echocardiographic images were acquired and then analyzed digitally by a single researcher blind of group information. Several parameters were measured by the leading edge technique including LV dimensions at diastole and systole (LVDd, LVDs), and wall thickness at diastole and systole. Fractional shortening (FS\%) was calculated as (LVDdLVDs)/LVDd. Fractional area change (FAC) was derived from end-diastolic and end-systolic areas of the short-axis loop, from the papillary muscle level and expressed as percentage change. Maximal aortic flow velocity was determined by Doppler imaging and the diameter of the ascending aorta measured. Cardiac output (CO) was calculated from mean AVF, aorta diameter, and heart rate. Due to higher levels of heart rate, particularly in relaxin-treated mice, we were unable to separate Doppler-derived LV filling flows (ie E and A waves) and therefore, LV diastolic function was not determined. ${ }^{17,21}$

Just prior to animal sacrifice (on days 7 and 30, respectively), arterial blood pressures and LV pressures were assessed on anesthetized mice by catheterization using a $1.4 \mathrm{Fr}$ Millar catheter, as described before. ${ }^{21}$ All mice were then killed by removal of the heart. Atria, right ventricle, and LV were separated and weighed. The entire LV was fixed in $2 \%$ 
paraformaldehyde containing $0.05 \%$ glutareldehyde for paraffin embedding and sectioning. The onset of cardiac rupture was monitored throughout the first 7 days post-MI and animals found dead were autopsied, as described previously. ${ }^{22}$ Cumulative survival curves (over the first 7 days post-MI) were also constructed by the Kaplan-Meier method.

\section{Histology and Morphometric Analysis}

Paraffin-embedded LV tissues were cut at $200 \mu \mathrm{m}$ intervals from the base to the apex of the LV and 15-20 serial sections ( $5 \mu \mathrm{m}$ thickness) were collected at each interval. Sections were stained with hematoxylin and eosin (H\&E) for assessment of general histology and IS, and with $0.1 \%$ Picrosirus red (Polysciences) for measurement of collagen (cardiac fibrosis). Sections from nine distinct regions of the heart: the NIR, border region (BR) and IR at the upper mid-zone, lower mid-zone, and apex were morphometrically analyzed; to determine if relaxin treatment was consistent or differed in these various regions.

For determination of IS, the length of the infarcted and non-infarcted segments of each serial sections of the LV was measured digitally using Optimas 6.2 Image analysis software (Optimas BioSac), and then averaged per treatment group. Based on the clear visibility of the scar area of the infarcted $\mathrm{LV}$, at both 7 days and 30 days post-MI, IS was calculated as the ratio of infarcted over the entire segment length. Serial sections were also used for immunohistochemical staining and morphometric analysis of various selected markers associated with collagen turnover, utilizing monoclonal antibodies to $\alpha$-smooth muscle actin ( $\alpha$-SMA; a marker for myofibroblast differentiation; 1:250 dilution; Dako) and MMP-13 (collagenase-3; 1:100 dilution, Calbiochem) in addition to a polyclonal antibody to TGF- $\beta 1$ (1:200 dilution, Santa-Cruz Biotechnology). Macrophage infiltration (inflammation) was assessed utilizing a monoclonal antibody to f4/80 (a transmembrane protein present on the cell surface of mouse macrophages; 1:50 dilution; Serotec); angiogenesis was detected by $\alpha$-SMA (smooth muscle) and glucose transporter (Glut-1; endothelial ${ }^{23}$ ) staining of vessels using a polyclonal antibody to Glut-1 (1:1000 dilution; Chemicon International); while cardiomyocyte apoptosis was detected using the ApopTag (TUNEL based) Plus Peroxidase assay kit (Millipore). Detection of antibody staining was completed using various DAB-based kits: the Vectastain ABC kit for $\alpha$-SMA, f4/80 and Glut-1, the Dako ARK (mouse on mouse) kit for MMP-13 and the Dako EnVision anti-rabbit kit for TGF- $\beta 1$.

For quantitative analysis of collagen, $\alpha$-SMA, TGF- $\beta 1$, MMP-13, f4/80, and TUNEL staining, representative images of these markers from each of the nine regions of the heart studied were digitally captured with a CCD video camera (Optimas BioSac). The area stained (from eight fields representing the NIR, BR, and IR for every $200 \mu \mathrm{m}$ section per tissue) was calculated as a percentage of the total area within the field. Apoptosis was determined by counting over 1000 cardiomyocyte nuclei per $\mathrm{LV}$, as described previously. ${ }^{24,25}$ Additionally, the effects of MI and RLX on angiogenesis were evaluated by counting the $\alpha$-SMA- and Glut- 1 (in structures that histologically resembled capillaries)-stained blood vessels in the NIR and BR of the various groups studied, and were expressed as the number of blood vessels per field. All analyses were independently performed by two investigators, in a blinded manner (and the data averaged in each case).

\section{Western Blot Analysis}

Total protein from the LV of sham-operated mice, and from the NIR and IR (which were separated with the aid of a surgical microscope) of MI + VEH and MI + RLX mice were extracted as described previously. ${ }^{10}$ Protein extracts (containing $20 \mu \mathrm{g}$ of total protein/lane) were then electrophoresed under non-reducing conditions on $12.5 \%$ acrylamide gels, as detailed before. ${ }^{10,11}$ Western blot analyses were performed with the monoclonal antibodies to $\alpha$-SMA (1:1000 dilution; Dako) and MMP-13 (1:1000 dilution; Calbiochem), the polyclonal antibody to TGF- $\beta 1$ (1:1000 dilution; Santa-Cruz Biotechnology), and goat anti-mouse or anti-rabbit IgG secondary antibodies, respectively. A monoclonal antibody to the housekeeping protein, $\alpha$-tubulin (1:1000 dilution; Sigma-Aldrich), was used to demonstrate equivalent loading of protein samples. Blots were detected using the ECL detection kit (Amersham Pharmacia Biotech; according to the manufacturer's instructions), before being quantified by densitometry using a Bio-Rad GS710 Calibrated Imaging Densitometer and Quantity-One software (Bio-Rad Laboratories).

\section{Statistical Analysis}

The results were analyzed by one-way ANOVA, using the Bonferroni post hoc test for comparisons between treatment groups (sham $v s \mathrm{MI}-\mathrm{VEH} / \mathrm{MI}+\mathrm{RLX}$ ) and furthermore by an independent $t$-test, to compare $\mathrm{MI}+\mathrm{VEH}$ vs $\mathrm{MI}+\mathrm{RLX}$ treated groups. A two-way ANOVA was also used to explore the interactions between IS groups (moderate/large) and treatment groups (VEH or RLX), or between treatment duration groups (7 day/30 day) and treatment groups (VEH or RLX). The Fisher exact test was used for comparison of percentages. Results are presented as the mean \pm s.e.m. with $P<0.05$ described as statistically significant.

\section{RESULTS \\ Surgical Outcomes, Mortality, Incidence of Pathological Events, and Organ Weights}

Of the 145 mice that were subjected to MI, 10 (6.9\% of the total number) underwent surgery-related deaths within $24 \mathrm{~h}$, $18(12.4 \%$ of animals with MI that survived surgery; $n=7$ $\mathrm{MI}+\mathrm{VEH}$ and $n=11 \mathrm{MI}+\mathrm{RLX}$ mice) died as a result of cardiac rupture and $4(n=1 \mathrm{MI}+\mathrm{VEH}$ and $n=3 \mathrm{MI}+\mathrm{RLX}$ mice) died of heart failure. Another $9(n=4 \mathrm{MI}+\mathrm{VEH}$ and $n=5 \mathrm{MI}+\mathrm{RLX})$ mice were lost during echocardiographic analysis due to heart failure. All 26 sham-operated animals 

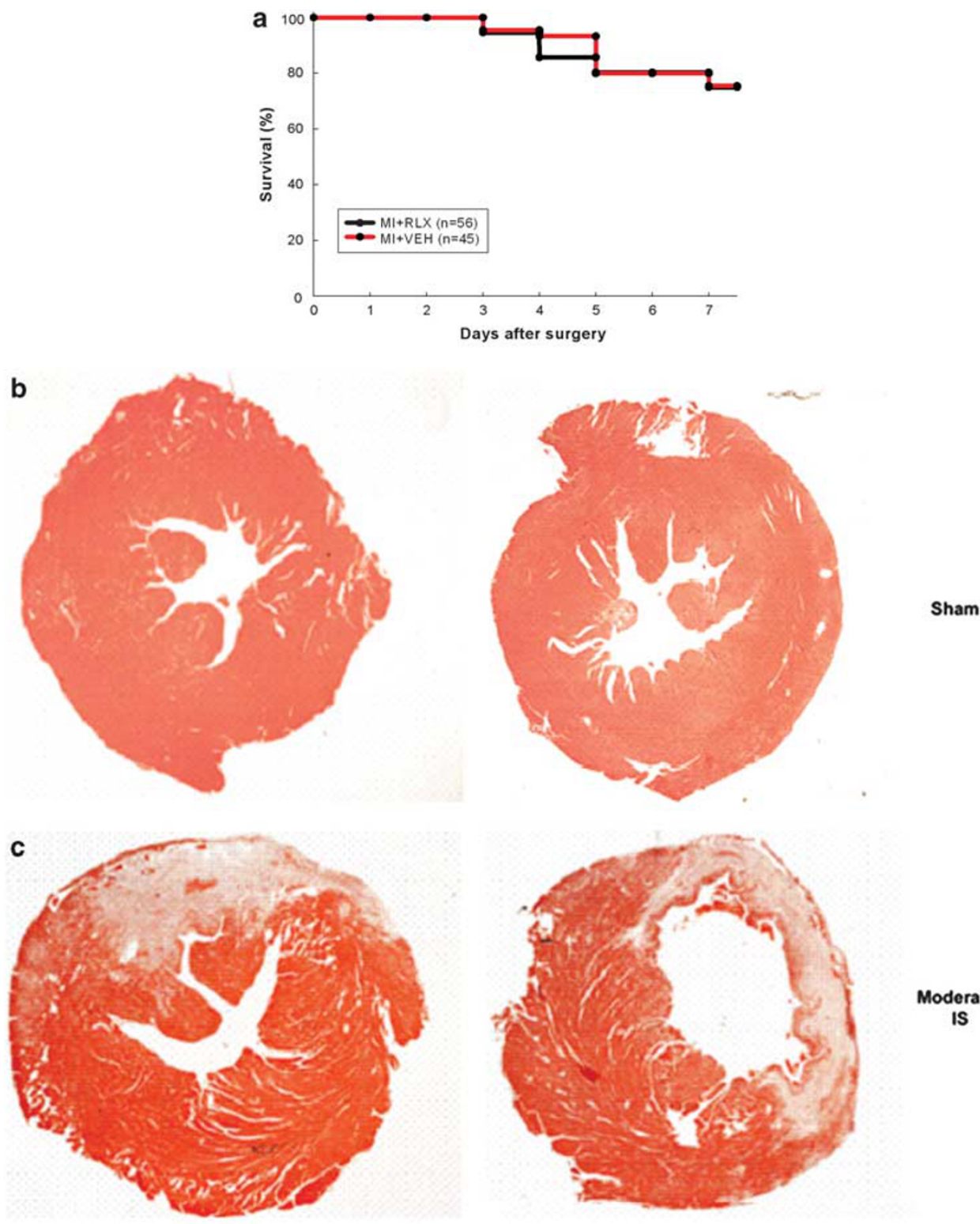

Moderate
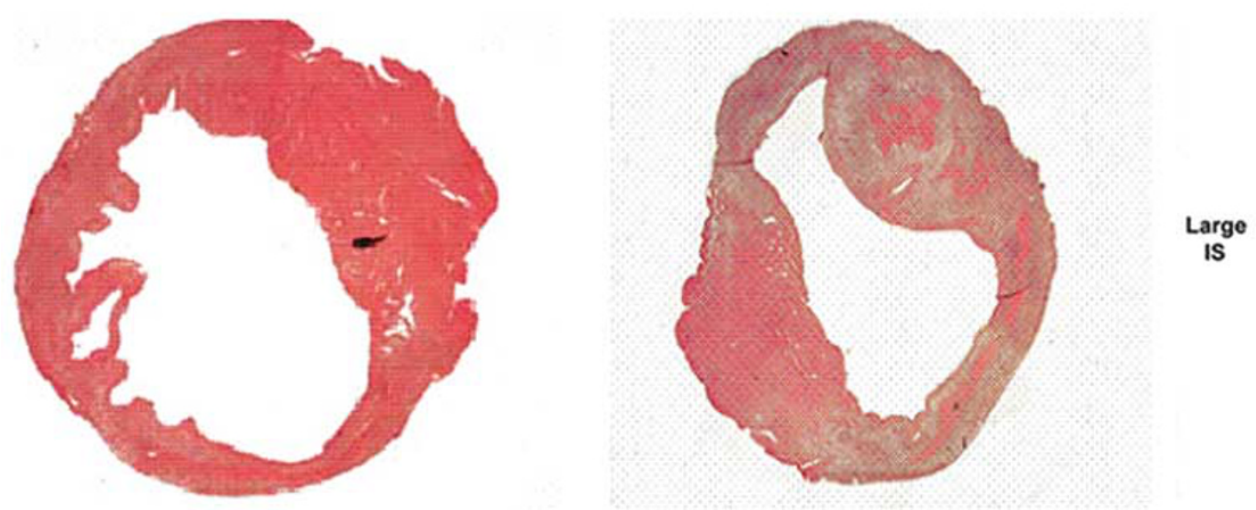

Figure 1 (a) Cumulative survival curves for MI-VEH vs MI-RLX mice (over the first 7 days post-MI), as generated by the Kaplan-Meier method. (b-d) Representative H\&E-stained LV sections from sham-operated mice at 7 days (left) and 30 days (right) post-MI (b); the mid-zone (left) and apex (right) of $\mathrm{MI}+\mathrm{VEH}$ mice with moderate and large infarct size at 7 days post-MI (c); and the mid-zone (left) and apex (right) of MI + VEH mice with moderate and large infarct size at 30 days post-MI (d). 

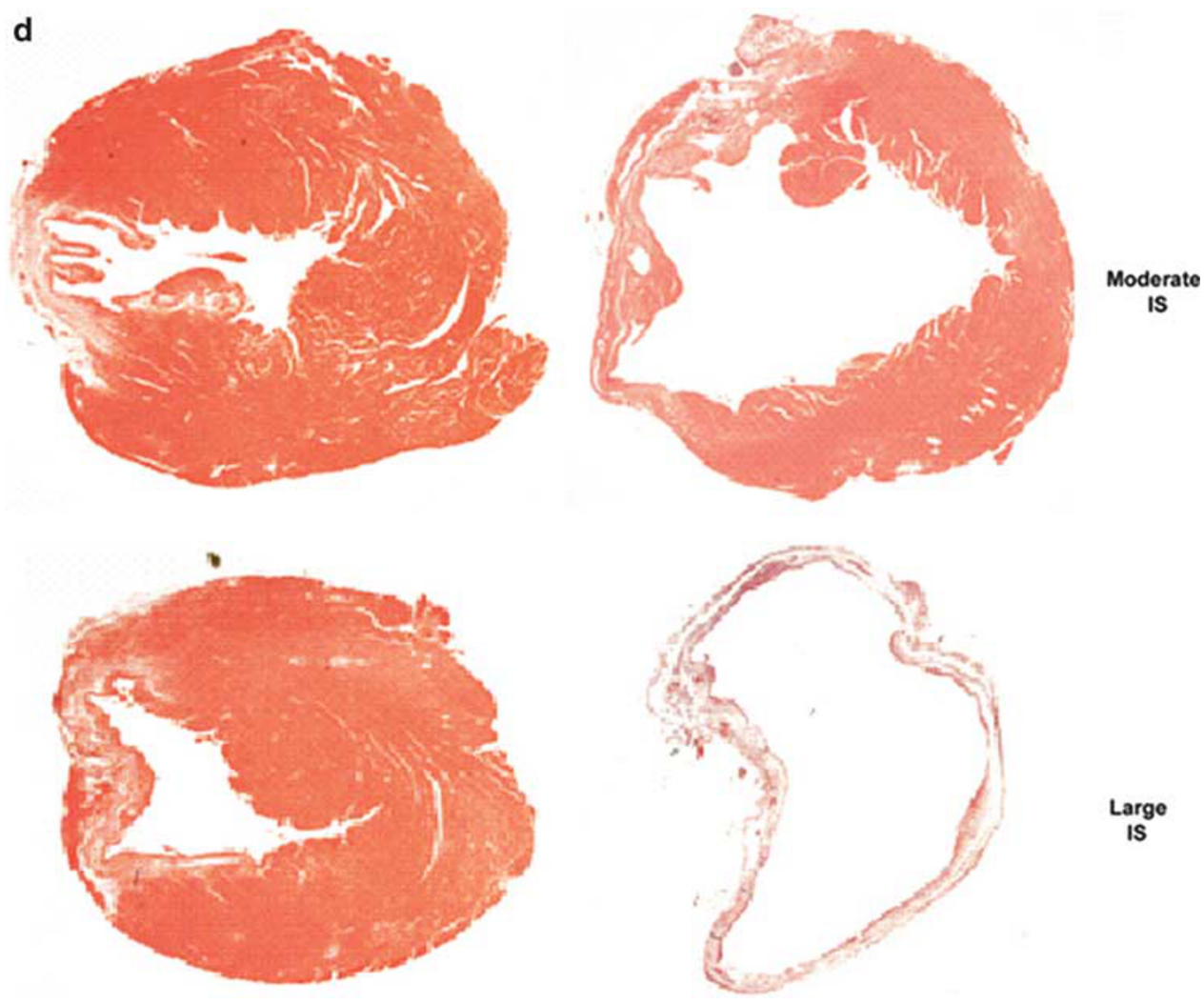

Figure 1 Continued.

survived the experimental time period. IS ranged from 5 to $60 \%$ (with all but 2 animals having an IS of $>15 \%$ ) and animals were also divided into moderate (IS ${ }^{\mathrm{M}}$ IS $<35 \%$ ) and large (IS ${ }^{\mathrm{L}}$ IS $>35 \%$ ) subgroups for detailed comparison. All mice with heart failure and 12/18 mice with cardiac rupture had a large IS $(>35 \%)$ post-MI. Importantly, relaxin treatment did not adversely affect the survival rate of animals (over 7 days post-MI; Figure 1a) or the incidence of cardiac rupture $(11 / 59=18.6 \%$ for $\mathrm{MI}+\mathrm{RLX}$ mice $v s 7 / 48=14.6 \%$ for $\mathrm{MI}+\mathrm{VEH}$ mice; $P=0.576)$. As a result, $n=58$ mice subjected to MI $(n=29 \mathrm{MI}+\mathrm{VEH}$ and $n=29 \mathrm{MI}+\mathrm{RLX})$ survived the 7-day experiment, while $n=46$ mice $(n=21$ $\mathrm{MI}+\mathrm{VEH}$ and $n=25 \mathrm{MI}+\mathrm{RLX})$ survived the 30-day experiment. While relaxin treatment modestly, but significantly reduced the size of the IR in mice with moderate IS, compared with that measured from corresponding vehicle-treated animals $(\mathrm{MI}+\mathrm{RLX}: \quad 24.4 \pm 1.5 \% \quad(n=26)$ vs $\mathrm{MI}+\mathrm{VEH}$ : $27.2 \pm 1.2 \%(n=27) ; P<0.05)$, this was not observed in mice with large IS (MI + RLX: $42.7 \pm 1.1 \%(n=20) v s \mathrm{MI}+\mathrm{VEH}$ : $43.2 \pm 1.0 \%(n=19))$.

Heart weight, LV weight, and LV/body weight ratio were all significantly increased in all infarcted groups compared with the sham-treated controls (all $P<0.05$ ) at both days 7 and 30 (Table 1). Lung weight was also significantly elevated $(P<0.05)$ in both MI groups 7 days post-surgery or tended to be higher in the 30-day MI groups. However, there were no significant differences in any of these parameters between the MI + VEH and MI + RLX groups, at either time point studied (Table 1).

\section{Functional Measurements}

The results of the echocardiography measurements are shown in Table 2. In both MI + VEH and MI + RLX groups studied at day 7 and day 30, LV diameter (LVDd), and LV area from short-axis images were significantly increased, while FS and FAC were significantly decreased, compared with respective measurements from sham-operated animals (all $P<0.05)$. A significant decrease in maximal aorta flow velocity, ejection time, and $\mathrm{CO}$ were also noted in the MI groups at day 7 postsurgery (all $P<0.05$ vs sham group). Overall, the IS was positively related to the extent of LV dysfunction as estimated from these parameters. LV area was significantly increased in all infarcted mice receiving either treatment at day 7 or day 30 compared relative to sham-operated controls $(P<0.05)$. No significant differences in LVd, FS, FAC, or CO were observed between MI + VEH and MI+ RLX groups. Relaxin-treated mice had a smaller LV area and lower AVF, changes very likely due to a significantly increased heart rate level $(P<0.05$ vs $\mathrm{MI}+\mathrm{VEH}$ groups at days 7 and 30), a finding consistent with previous reports in other rodent models. ${ }^{18,26}$

Hemodynamic measurements (Table 3) confirmed the relaxin-induced increment in heart rate at days 7 and 30 $(P<0.01$ vs sham and $\mathrm{MI}+\mathrm{VEH}$ groups $)$. MI resulted in 
Table 1 Organ weights of sham- and LCA-operated mice

\begin{tabular}{|c|c|c|c|c|c|c|}
\hline & \multicolumn{3}{|c|}{ Day 7} & \multicolumn{3}{|c|}{ Day 30} \\
\hline & SHAM & $\mathrm{Ml}+\mathrm{VEH}$ & $\mathrm{MI}+\mathrm{RLX}$ & SHAM & $\mathrm{Ml}+\mathrm{VEH}$ & $\mathrm{Ml}+\mathrm{RLX}$ \\
\hline$n$ & 11 & 23 & 23 & 9 & 21 & 24 \\
\hline BW, g & $30.7 \pm 0.3$ & $30.2 \pm 0.4$ & $30.3 \pm 0.5$ & $32.8 \pm 0.7$ & $32.5 \pm 0.4$ & $33.7 \pm 0.3$ \\
\hline$I^{\mathrm{L}}$ & - & $29.9 \pm 0.4$ & $29.8 \pm 0.5$ & - & $32.2 \pm 0.4$ & $33.4 \pm 0.3$ \\
\hline HW, mg & $143 \pm 4$ & $177 \pm 4^{* *}$ & $182 \pm 6^{* *}$ & $155 \pm 5$ & $198 \pm 5^{* *}$ & $195 \pm 6^{* *}$ \\
\hline $1 S^{M}$ & - & $165 \pm 3$ & $186 \pm 5$ & - & $185 \pm 4$ & $182 \pm 6$ \\
\hline $\mathrm{IS}^{\mathrm{M}}$ & - & $125 \pm 3$ & $135 \pm 3$ & - & $141 \pm 3$ & $134 \pm 5$ \\
\hline$I^{L}$ & - & $134 \pm 3$ & $129 \pm 4$ & - & $152 \pm 3$ & $147 \pm 4$ \\
\hline LV/BW, mg/g & $3.48 \pm 0.10$ & $4.30 \pm 0.10^{* *}$ & $4.35 \pm 0.10^{* *}$ & $3.62 \pm 0.09$ & $4.53 \pm 0.09^{* *}$ & $4.23 \pm 0.12^{x}$ \\
\hline $\mathrm{IS}^{\mathrm{M}}$ & - & $4.09 \pm 0.10$ & $4.39 \pm 0.07$ & - & $4.29 \pm 0.09$ & $3.95 \pm 0.11$ \\
\hline $\mathrm{IS}^{\mathrm{L}}$ & - & $4.44 \pm 0.08$ & $4.32 \pm 0.12$ & - & $4.72 \pm 0.06$ & $4.41 \pm 0.11$ \\
\hline Lung, mg & $172 \pm 4$ & $214 \pm 9^{*}$ & $206 \pm 8^{*}$ & $176 \pm 6$ & $213 \pm 15$ & $208 \pm 9$ \\
\hline $\mathrm{IS}^{\mathrm{M}}$ & - & $177 \pm 3$ & $198 \pm 9$ & - & $179 \pm 4$ & $184 \pm 3$ \\
\hline
\end{tabular}

BW: body weight; HW: heart weight; $\mathrm{IS}^{\mathrm{M}}$ and $\mathrm{IS}^{\mathrm{L}}$ : animals with moderate or large infarct size; LV: left ventricle.

Data are presented as the mean \pm s.e.m.

${ }^{*} P<0.05,{ }^{*} P<0.01$ vs sham group.

elevated LV end-diastolic pressure (LVEDP) and Tau (diastolic dysfunction) and decreased LV systolic pressure (LVSP), $\mathrm{d} P / \mathrm{d} t_{\min }$, systolic arterial pressure and pulse pressure, 7 and 30 days post-surgery (all $P<0.05 v s$ sham group). Relaxin treatment resulted in a significant decrease in LVEDP after 7 and 30 days $(P<0.01 v s \mathrm{MI}+\mathrm{VEH}$ group $)$, but had no detectable effects on other measures of LV diastolic (such as Tau and $\left.\mathrm{d} P / \mathrm{d} t_{\min }\right)$ or systolic functional parameters.

\section{The Effects of Relaxin on MI-Induced Cardiac Remodeling}

H\&E staining of heart tissue from sham- (Figure 1b) and MI (Figures $1 \mathrm{c}$ and $\mathrm{d}$ )-induced mice revealed a reduction of ventricular wall thickness and myocardial integrity in infarcted mice with moderate and large IS over the 30-day experimental period, compared with that observed in shamoperated animals. Picrosirus red staining of the myocardium was then used to detect changes in collagen staining in various regions of the heart: the NIR, BR, and IR at the upper mid-zone, lower mid-zone, and apex (Figure 2). A signifi- cant increase in collagen staining was measured in the NIR (by twofold at the apex only), BR (by 4-6-fold), and IR (by 15-21-fold) of day $7 \mathrm{MI}+\mathrm{VEH}$ mice, and in the NIR (by 2.75 -fold at the apex only), BR (by $8-10$-fold), and IR (by $25-30$-fold) of day $30 \mathrm{MI}+\mathrm{VEH}$ mice compared with that measured in sham controls (all $P<0.05$ ), regardless of IS (Figure 2). Importantly, the presence of $\mathrm{H} 2$ relaxin uniformly reduced the post-infarct collagen density in the IR by $30-35 \%$ of that measured in MI + VEH mice over 7 and 30 days, while also inhibiting cardiac fibrosis in the BR by $60-75 \%$ and NIR by $90 \%$ of that measured in MI + VEH mice over 30 days, independently of IS (all $P<0.05$ vs respective $\mathrm{MI}+\mathrm{VEH}$ measurements).

At 7 days after MI, macrophage infiltration was primarily increased in the IR (by threefold) and to a lesser degree in the $\mathrm{BR}$ of MI + VEH mice, 7 days post-surgery (all $P<0.05 v s$ respective sham measurements; Figure 3a), and was then markedly reduced in the myocardium of day $30 \mathrm{MI}+\mathrm{VEH}$ mice, as mature scar tissue began to increasingly replace the IR; however, the levels of $\mathrm{f} 4 / 80$ staining were still significantly 
Table 2 Echocardiography measurements of sham-operated and infarcted mice

\begin{tabular}{|c|c|c|c|c|c|c|}
\hline & \multicolumn{3}{|c|}{ Day 7} & \multicolumn{3}{|c|}{ Day 30} \\
\hline & SHAM & $\mathrm{Ml}+\mathrm{VEH}$ & MI+RLX & SHAM & $\mathrm{Ml}+\mathrm{VEH}$ & $\mathrm{Ml}+\mathrm{RLX}$ \\
\hline$n$ & 11 & 23 & 23 & 9 & 21 & 24 \\
\hline $\mathrm{HR}$, beats/min & $463 \pm 15$ & $411 \pm 13^{*}$ & $486 \pm 11^{\dagger \dagger}$ & $471 \pm 12$ & $458 \pm 13$ & $512 \pm 10^{\dagger}$ \\
\hline$I^{L}$ & - & $418 \pm 10$ & $491 \pm 9^{\dagger}$ & - & $461 \pm 15$ & $510 \pm 10$ \\
\hline LVDd, mm & $4.69 \pm 0.15$ & $5.97 \pm 0.19^{* *}$ & $5.70 \pm 0.17^{\star *}$ & $4.64 \pm 0.14$ & $6.32 \pm 0.17^{\star *}$ & $6.09 \pm 0.16^{* *}$ \\
\hline $\mathrm{IS}^{\mathrm{M}}$ & - & $5.33 \pm 0.12$ & $5.55 \pm 0.15$ & - & $5.71 \pm 0.11$ & $5.43 \pm 0.12$ \\
\hline $\mathrm{IS}^{\mathrm{M}}$ & - & $22.7 \pm 1$ & $18.2 \pm 2$ & - & $21.7 \pm 1$ & $20.9 \pm 1$ \\
\hline$I^{L}$ & - & $12.1 \pm 2$ & $17.7 \pm 2$ & - & $14.3 \pm 1$ & $11.1 \pm 1$ \\
\hline LVArea, $\mathrm{mm}^{2}$ & $15.2 \pm 0.8$ & $22.9 \pm 1.2^{*}$ & $20.2 \pm 1.1^{*}$ & $13.5 \pm 0.8$ & $26.9 \pm 1.2^{*}$ & $24.2 \pm 1.2^{*}$ \\
\hline $1 S^{M}$ & - & $19.5 \pm 1.0$ & $20.0 \pm 0.8$ & - & $22.9 \pm 0.7$ & $18.6 \pm 0.7^{\dagger}$ \\
\hline$I^{L}$ & - & $25.3 \pm 1.0$ & $20.4 \pm 1.3^{\dagger}$ & - & $29.9 \pm 1.1$ & $27.6 \pm 1.0$ \\
\hline FAC, $\%$ & $38 \pm 2$ & $24 \pm 2^{*}$ & $23 \pm 2^{*}$ & $37 \pm 2$ & $23 \pm 2^{* *}$ & $20 \pm 1^{* *}$ \\
\hline$I^{M}$ & - & $30 \pm 2$ & $27 \pm 2$ & - & $26 \pm 2$ & $26 \pm 1$ \\
\hline $\mathrm{ET}, \mathrm{ms}$ & $150 \pm 4$ & $138 \pm 2^{*}$ & $135 \pm 3^{*}$ & $146 \pm 4$ & $142 \pm 2$ & $131 \pm 4^{\dagger}$ \\
\hline$I S^{M}$ & - & $138 \pm 2$ & $137 \pm 3$ & - & $142 \pm 2$ & $137 \pm 2$ \\
\hline$I^{L}$ & - & $138 \pm 3$ & $133 \pm 4$ & - & $142 \pm 2$ & $128 \pm 4$ \\
\hline $\mathrm{CO}, \mathrm{ml} / \mathrm{min}$ & $13.9 \pm 1.0$ & $9.0 \pm 0.6^{*}$ & $8.3 \pm 0.7^{* *}$ & $11.7 \pm 1.7$ & $10.4 \pm 0.9$ & $8.7 \pm 0.8$ \\
\hline $\mathrm{IS}^{\mathrm{M}}$ & - & $10.3 \pm 0.8$ & $9.2 \pm 0.5$ & - & $11.8 \pm 1.0$ & $10.1 \pm 1.0$ \\
\hline $\mid S^{L}$ & - & $8.1 \pm 0.4$ & $7.5 \pm 0.8$ & - & $9.2 \pm 0.8$ & $7.9 \pm 0.7$ \\
\hline
\end{tabular}

AV: maximum aorta flow velocity; CO: cardiac output; ET: ejection time; FAC: fractional area change; FS: fractional shortening; $\mathrm{HR}$ : heart rate; IS ${ }^{\mathrm{M}}, \mathrm{IS}^{\mathrm{L}}$ : animals with moderate or large infarct size; LVd: left ventricular diameter.

Data are presented as the mean \pm s.e.m.

${ }^{*} P<0.05,{ }^{*} P<0.01$ vs sham group; ${ }^{\dagger} P<0.05,{ }^{\dagger \dagger} P<0.01$ vs MI-VEH group.

higher in the IR (by twofold; $P<0.05$ ) and to a lesser degree in the BR of day $30 \mathrm{MI}+\mathrm{VEH}$ mice, compared with that measured in day 30 sham-operated animals. Relaxin treatment had no significant effect on macrophage infiltration in all LV regions at both time points studied (Figure 3a).
TGF- $\beta 1$ immunostaining (Figure $3 \mathrm{~b}$ ) and expression (Figure 4) was also significantly increased in the IR (by 15-25-fold and 30-40-fold; both $P<0.01$ vs sham measurements) and BR (by $4-5$-fold and $10-15$-fold; both $P<0.05$ vs sham measurements) of day 7 and day $30 \mathrm{MI}+\mathrm{VEH}$ mice, respectively, 
Table 3 Hemodynamic measurements of sham-operated and infarcted mice

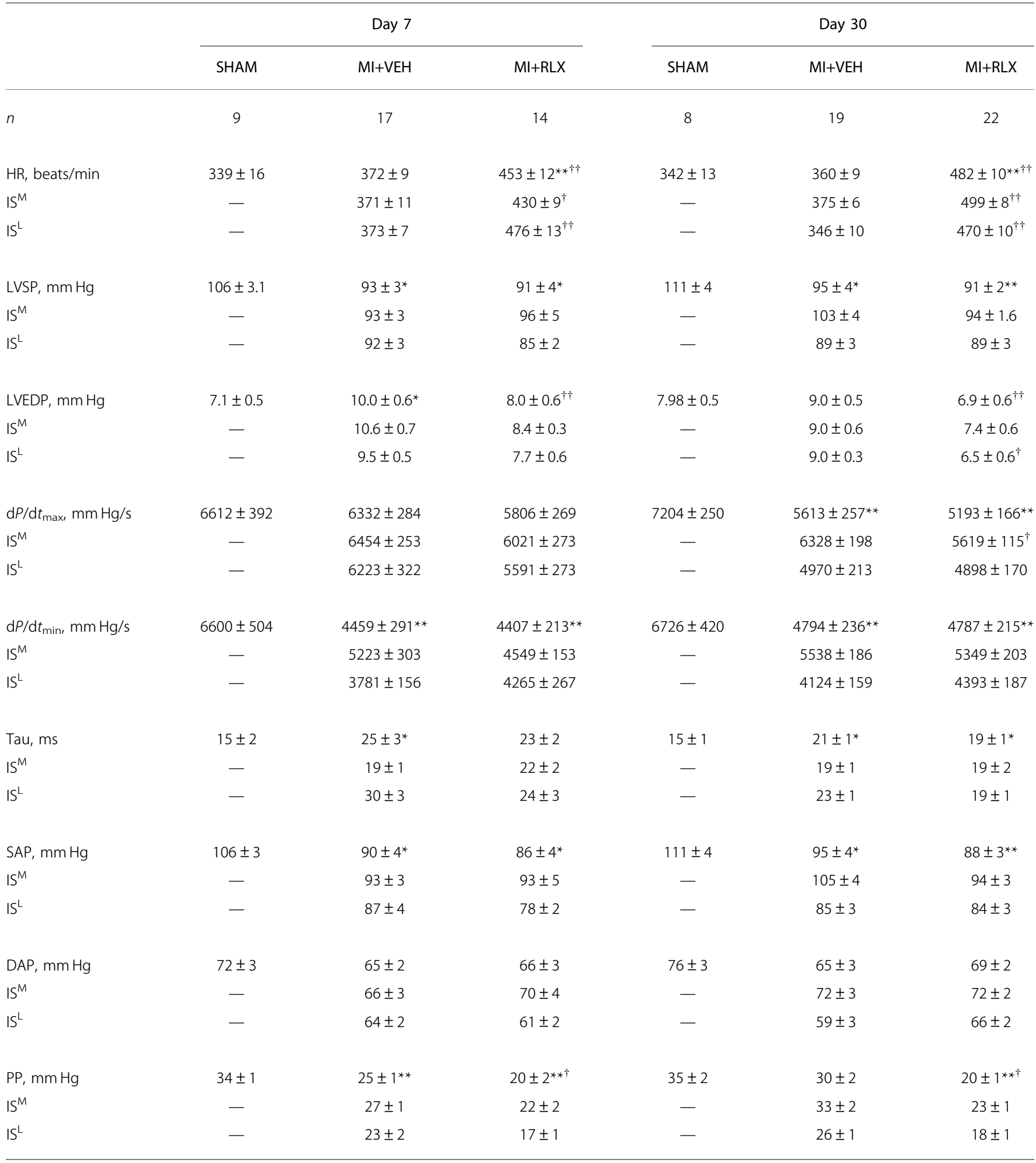

DAP: diastolic arterial pressure; HR: heart rate; $\mathrm{IS}^{\mathrm{M}}$ and $\mathrm{IS}^{\mathrm{L}}$ : animals with moderate or large infarct size; LVEDP: LV end-diastolic pressure; LVSP: LV systolic pressure; PP: pulse pressure; SAP: systolic arterial pressure.

Data are presented as the mean \pm s.e.m.

${ }^{\star} P<0.05,{ }^{* *} P<0.01$ vs sham group; ${ }^{\dagger} P<0.05,{ }^{\dagger} P<0.01$ vs MI-VEH group. 

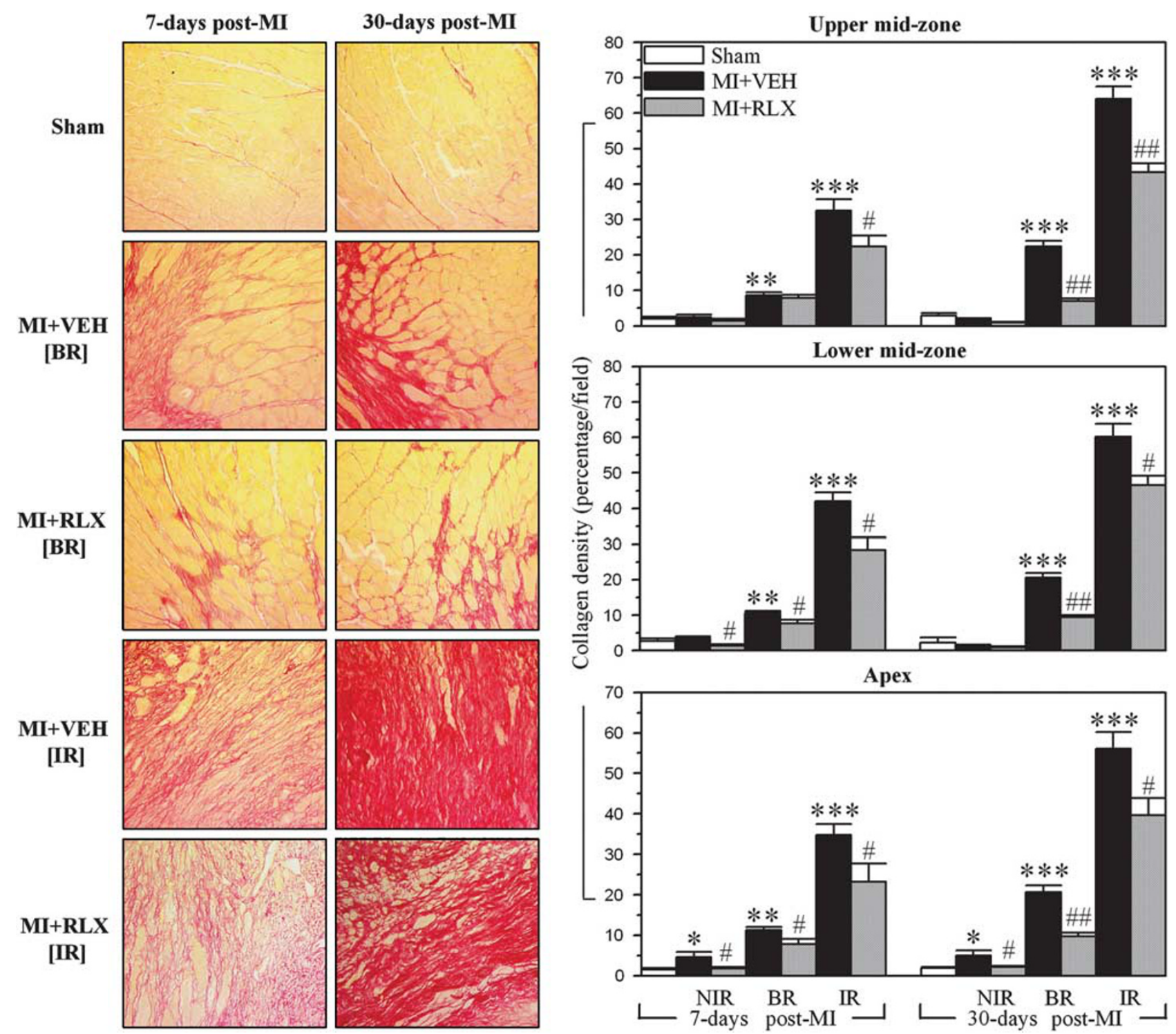

Figure 2 Representative images of picrosirus-red-stained collagen (a measure of cardiac fibrosis) from the BR and IR of sham-operated mice, in addition to $\mathrm{MI}+\mathrm{VEH}$ and $\mathrm{MI}+\mathrm{RLX}$ mice, at 7 and 30 days post-MI. Also shown is the mean \pm s.e. collagen density (estimated by computer-aided morphometry and expressed as a percentage per field; from eight fields representing the NIR, BR, and IR; from the upper mid-zone, lower mid-zone, and apex of the heart of sham, $\mathrm{MI}+\mathrm{VEH}$ and $\mathrm{MI}+\mathrm{RLX}$ animals ( $n=9-12 /$ group), at 7 and 30 days post-MI. ${ }^{*} P<0.05,{ }^{* * P}<0.01,{ }^{* * * P}<0.001$ vs respective sham-operated group; ${ }^{\#}<<0.05,{ }^{\# \#} P<0.01$ vs respective $\mathrm{Ml}+\mathrm{VEH}$ group.

in a similar manner to that of collagen. Likewise, $\alpha$-SMA expression (Figures 4 and $5 \mathrm{a}$ ) was significantly elevated in the IR (by 30-50-fold), BR (by 10-15-fold) and NIR (by 4.5 -fold at the apex only; all $P<0.05$ vs sham measurements) of day $7 \mathrm{MI}+\mathrm{VEH}$, but was markedly reduced in the myocardium of day $30 \mathrm{MI}+\mathrm{VEH}$ mice (compared with that measured in day $7 \mathrm{MI}+\mathrm{VEH}$ animals). In comparison, 7 day $\mathrm{MI}+\mathrm{RLX}$ mice had a $45-50 \%$ decrease in apical TGF- $\beta 1$ expression $(P<0.05$; Figures $3 \mathrm{~b}$ and 4$)$ and up to a $75 \%$ decrease in $\alpha$-SMA expression (in the mid-zone; $P<0.05$; Figure 5a) compared with that measured in 7 day $\mathrm{MI}+\mathrm{VEH}$ animals. Furthermore, 30 day MI + RLX mice continued to have a significant reduction in TGF- $\beta 1$ staining in the IR and BR (by $30-60 \%$ of that in MI + VEH mice; $P<0.05$; Figure $3 \mathrm{~b})$, while also significantly decreasing the levels of $\alpha$-SMA expression in the NIR of the heart $(P<0.05$; Figure 5a). These combined findings suggested that one means by which relaxin was inhibiting MI-induced cardiac fibrosis was via inhibition of TGF- $\beta 1$.

MMP-13 staining (Figure $5 \mathrm{~b}$ ) in addition to latent and active levels of MMP-13 (Figure 4) were progressively increased in the IR (by 8-10-fold and 15-25-fold; both $P<0.05$ vs sham measurements) and BR (by 3-5-fold and 6-10-fold; both $P<0.05$ vs sham measurements) of day 7 and day 30 
a
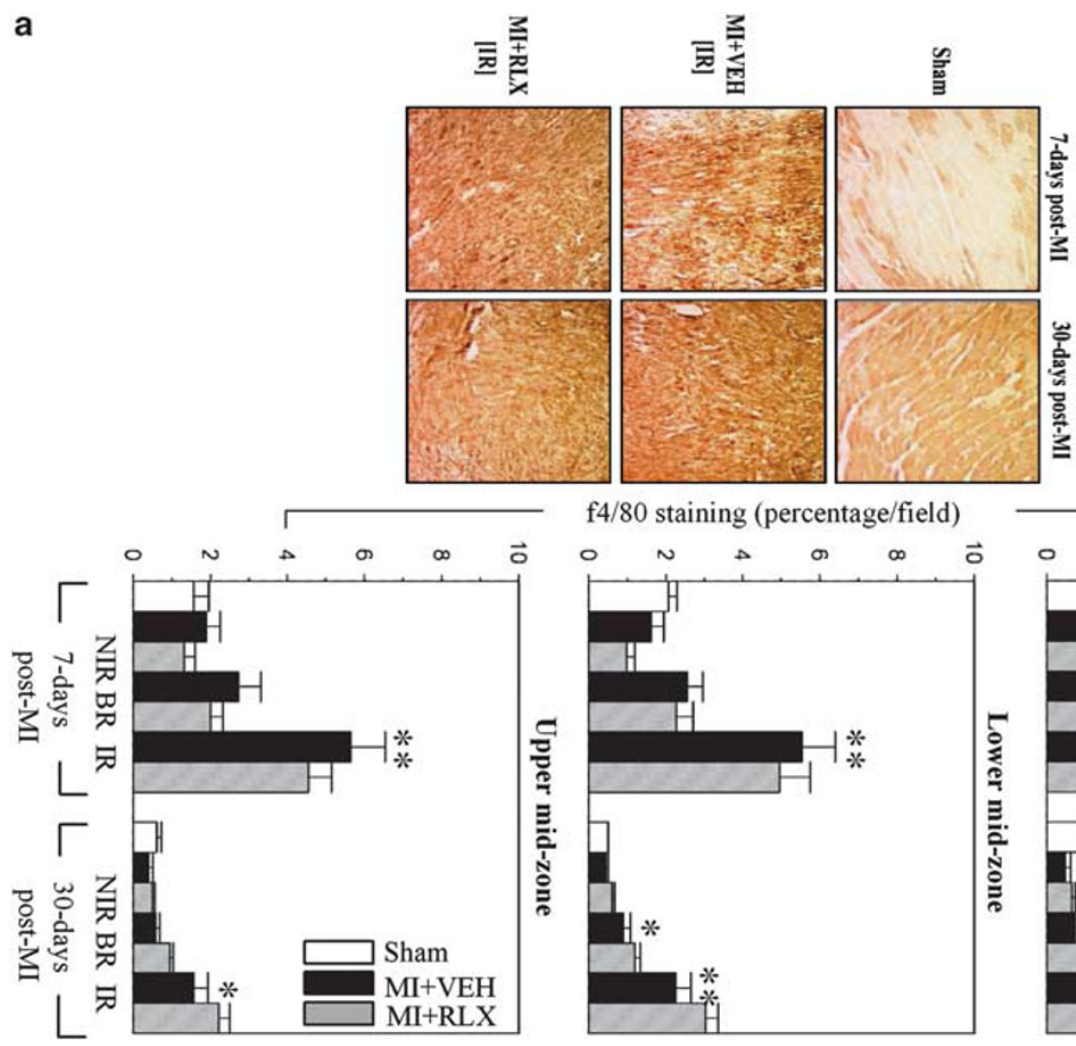

$\mathrm{f} 4 / 80$ staining (percentage/field)
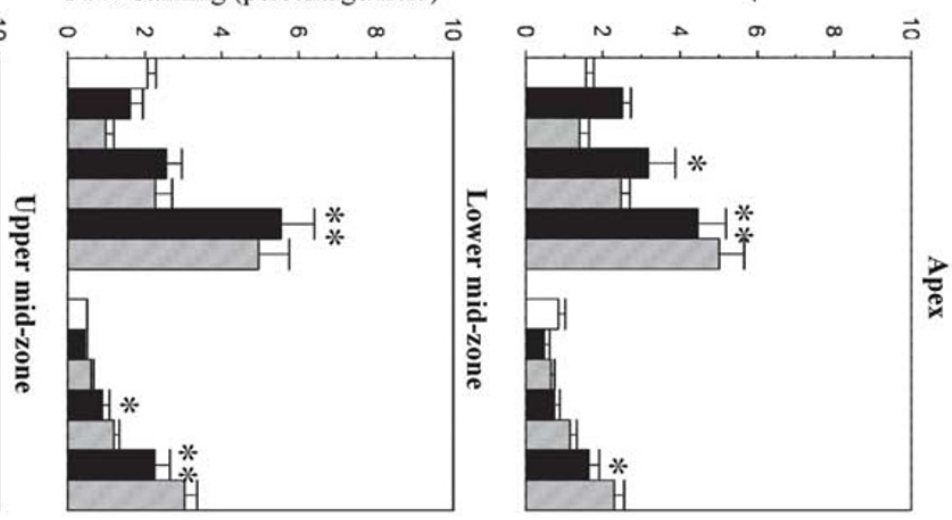

b
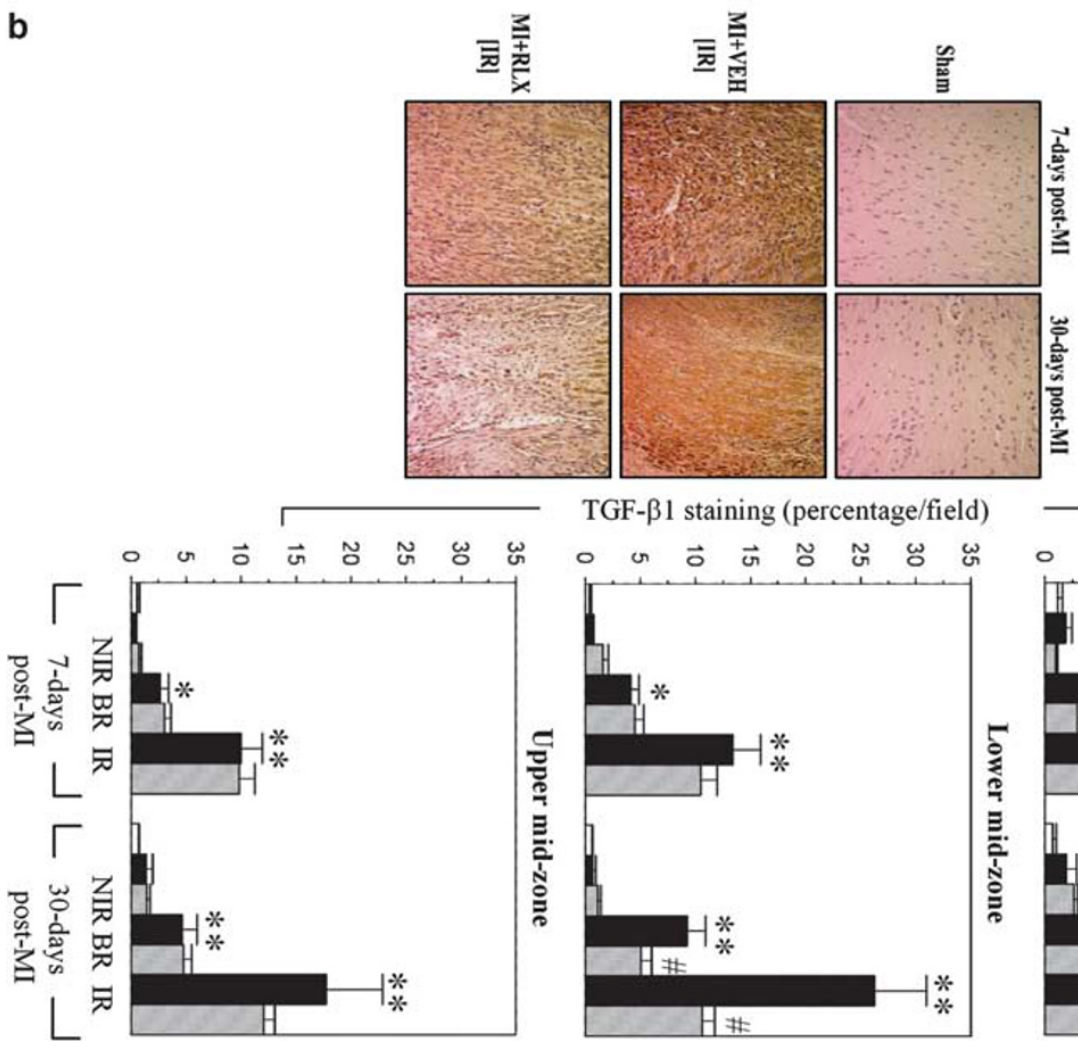

TGF- $\beta 1$ staining (percentage/field)

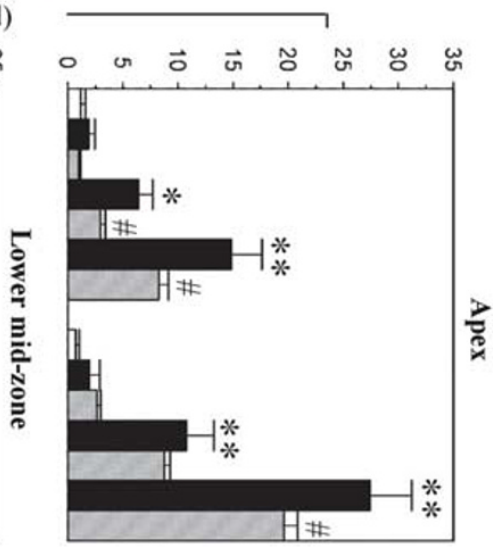

Figure 3 (a) Representative images of $\mathrm{f} 4 / 80$ (a marker of macrophage infiltration) and (b) TGF- $\beta 1$ staining from sham-operated mice, and from the IR of MI-VEH and MI-RLX mice at 7 and 30 days post-MI. Also shown is the mean \pm s.e. (a) f4/80 and (b) TGF- $\beta 1$ density (expressed as a percentage per field) from eight fields representing the NIR, BR, and IR, from the upper mid-zone, lower mid-zone, and apex of the heart of sham, $\mathrm{MI}+\mathrm{VEH}$ and $\mathrm{MI}+\mathrm{RLX}$ animals ( $n=9-12 /$ group), at 7 and 30 days post-MI. ${ }^{*} P<0.05,{ }^{*} P<0.01$ vs respective sham-operated group; ${ }^{\#} P<0.05$ vs respective $\mathrm{MI}+\mathrm{VEH}$ group. 

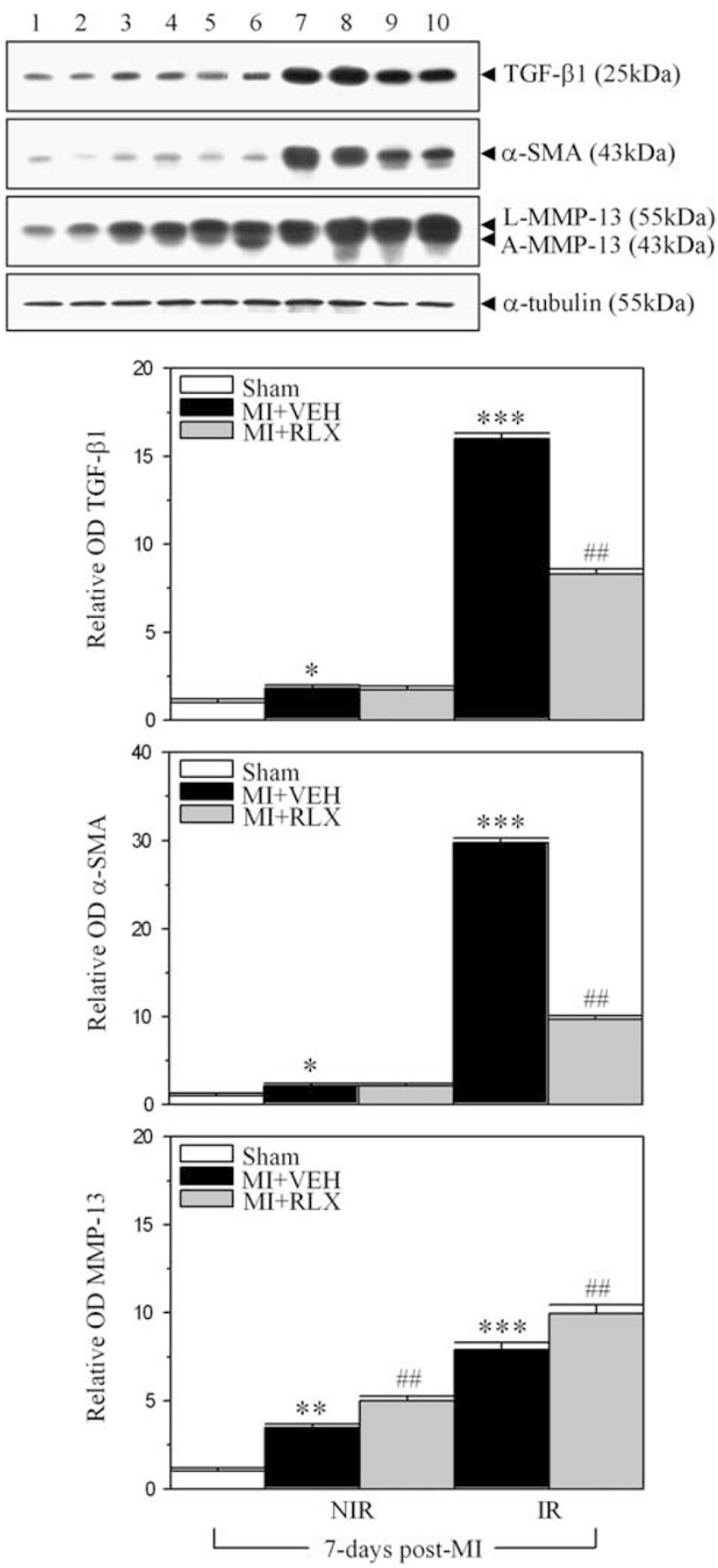

Figure 4 Representative western blots of TGF- $\beta 1$ ( $25 \mathrm{kDa}), \alpha-\mathrm{SMA}(43 \mathrm{kDa})$ and MMP-13 (showing latent ( $55 \mathrm{kDa}$ ) and active ( $43 \mathrm{kDa}$ ) forms of MMP-13) from the LV of sham-operated mice (lanes 1 and 2), in addition to the NIR (lanes 3 and 4) and IR (lanes 7 and 8) of MI + VEH mice and NIR (lanes 5 and 6) and IR (lanes 9 and 10) of MI + RLX animals, at 7 days post-MI. A representative western blot of $\alpha$-tubulin ( $55 \mathrm{kDa}$ ) from the corresponding LV regions assessed was used to demonstrate the quality and equivalent loading of protein samples. Also shown are the mean \pm s.e. levels of TGF- $\beta 1$, $\alpha$-SMA and MMP-13, which was determined by densitometry from $n=6$ animals per group, and expressed as a relative ratio to the mean value of each parameter measured in the sham-operated group, which was expressed as 1. ${ }^{*} P<0.05,{ }^{* * P}<0.01,{ }^{* *} P<0.001$ vs sham-operated group; ${ }^{\#} P<0.05,{ }^{\# \#} P<0.01$ vs respective $\mathrm{MI}+\mathrm{VEH}$ group.
$\mathrm{MI}+\mathrm{VEH}$ mice, respectively. Relaxin therapy further increased MMP-13 levels at day 7 (by $25-40 \%$ in the IR and by $45-60 \%$ in the BR of that measured in day $7 \mathrm{MI}+\mathrm{VEH}$ animals; all $P<0.05$ ) and to a greater extent at day 30 (by 2-3-fold of that measured in day $30 \mathrm{MI}+\mathrm{VEH}$ animals; all $P<0.05$ ) (Figures 4 and $5 \mathrm{~b}$ ), suggesting that relaxin was able to upregulate the primary interstitial collagenase that is known to degrade collagen in the rodent heart.

The potential effects of relaxin therapy on angiogenesis and myocyte apoptosis were also assessed. $\alpha$-SMA- (Figure 6a) and Glut-1- (Figure 6b)-stained blood vessel counts were both increased in the BR of MI + VEH mice at days 7 and 30 post-MI (both $P<0.05 v s$ respective sham measurements). Consistent with its previously reported angiogenic actions, ${ }^{15}$ relaxin administration to mice significantly increased blood vessel counts in the BR (by 30-60\%) after 7 and 30 days of treatment and in the mid-zone of the NIR (by twofold) after 30 days of treatment (all $P<0.05 v s$ respective measurements from MI + VEH mice; Figure 6). A significant increase in cardiomyocyte apoptosis (by TUNEL staining) was also evident in the BR of MI + VEH mice by 30 days post-MI, while the number of cardiomyocytes undergoing apoptosis was significantly inhibited in MI + RLX animals $(P<0.05$ vs measurements from MI + VEH mice; Figure 7) over the same time period.

\section{DISCUSSION}

In this study, we have demonstrated that relaxin treatment simultaneously remodeled post-infarct healing and the extracellular matrix of the non-infarct myocardium independent of IS. Specifically, relaxin therapy markedly reduced the density of collagen in the infarct zone and reduced interstitial fibrosis in other regions of the $\mathrm{LV}$, while promoting angiogenesis at acute and chronic phases of MI. Furthermore, relaxin treatment significantly reduced the level of cardiomyocyte apoptosis during chronic MI. Importantly, relaxin therapy did not adversely affect animal survival rate, the incidence of ventricular rupture, nor the extent of MI-induced LV remodeling or dysfunction during acute and chronic phases of MI.

We studied mice at day 7 and day 30 post-infarction, representing time points of early and mature fibrotic healing. To estimate the effects of relaxin treatment on different regions of the infarcted heart, we performed comprehensive histochemical and morphometric analyses within the noninfarct, border, and infarct regions; to address the uniformity of relaxin's effects and to overcome the difficulties of obtaining sufficient amounts of tissue from each region for evaluation by relatively insensitive biochemical assays. The extent of post-infarct ventricular remodeling in the murine model is time and IS dependent. ${ }^{17,27,28} \mathrm{LV}$ dilatation, estimated from increments in LV dimension and cross-sectional area by echocardiography, was greater in groups with chronic than acute infarct. At both time points studied, the extent of LV size and dysfunction was dependent on IS, as reported in 
a
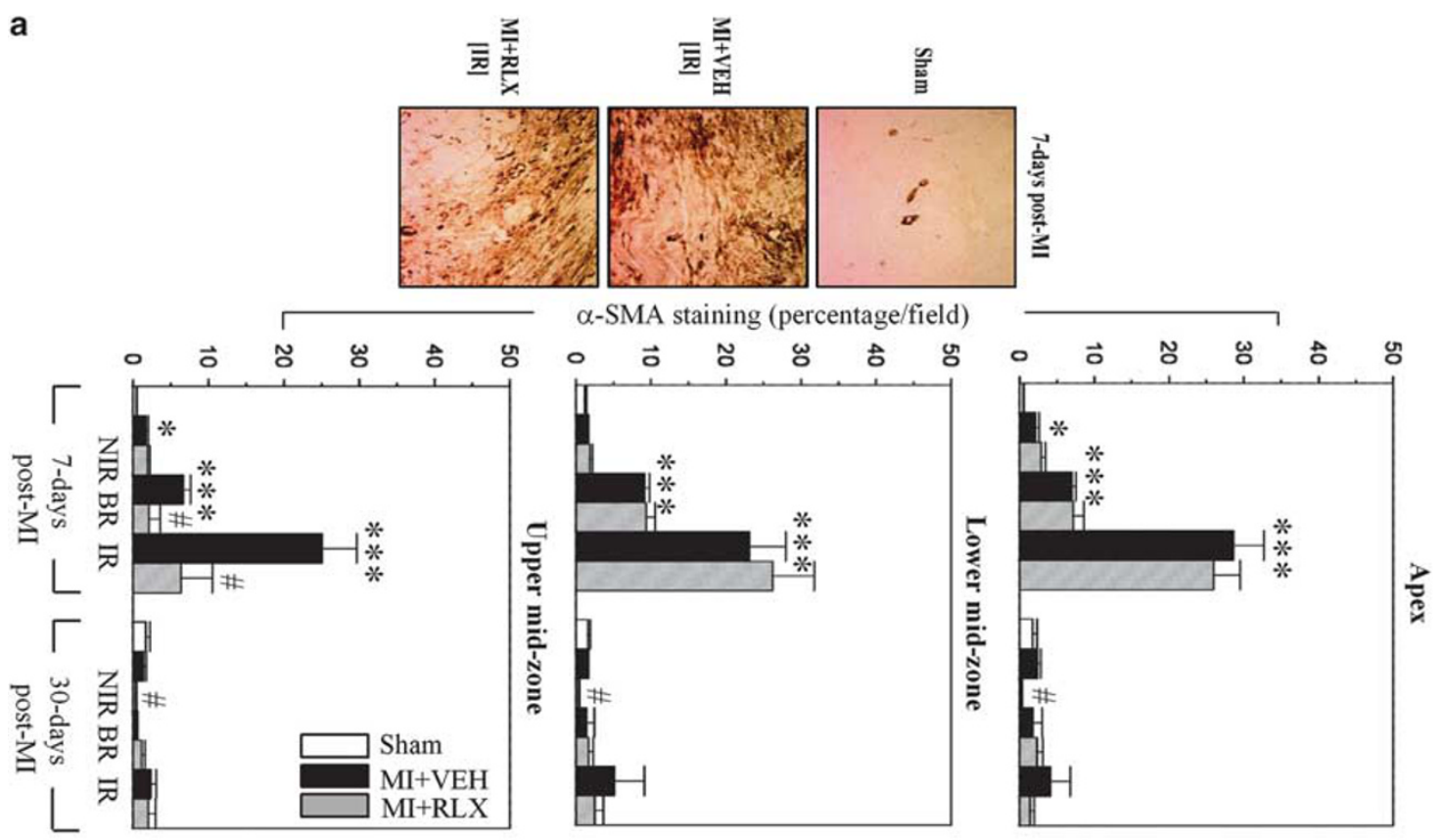

b
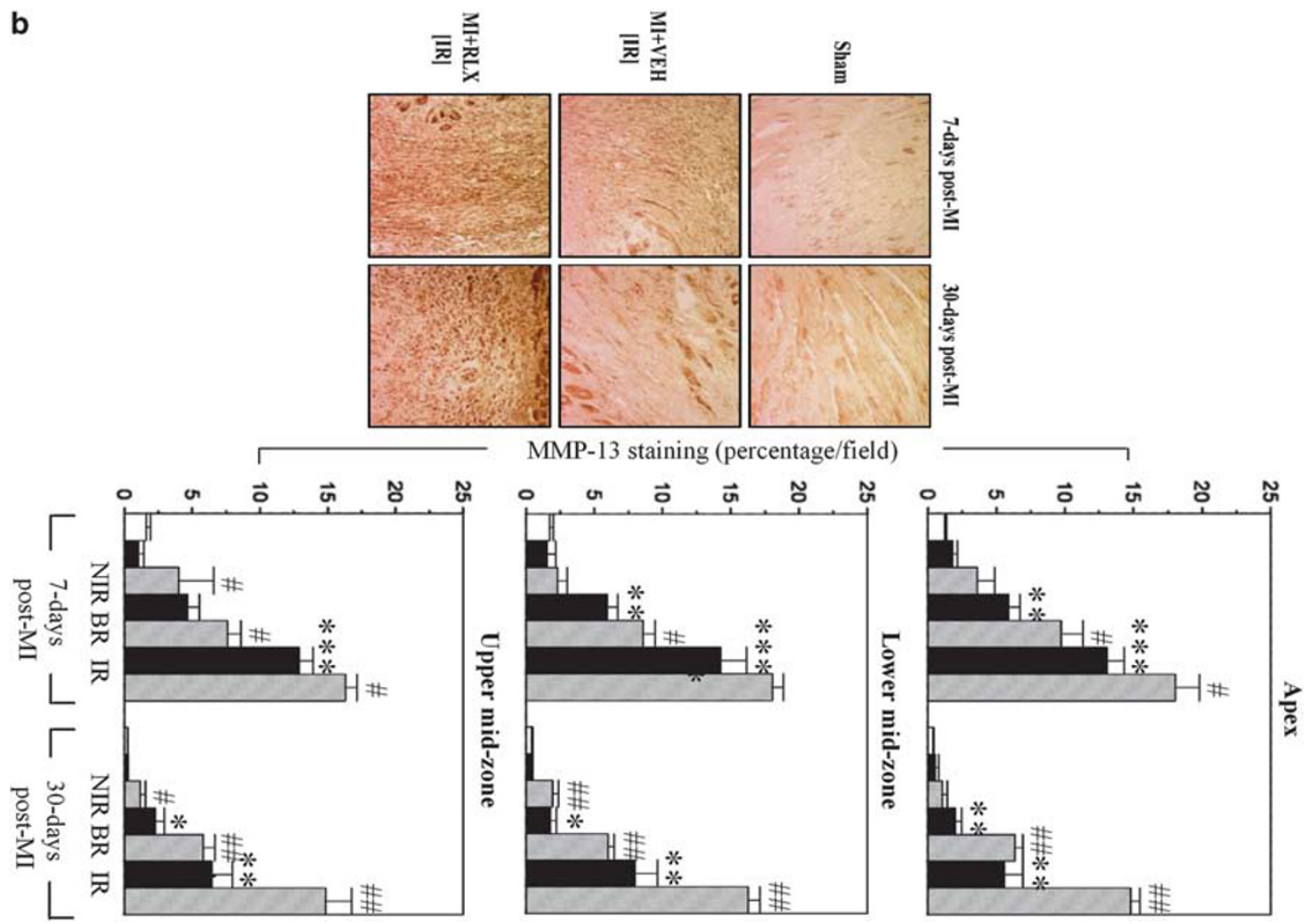

Figure 5 (a) Representative images of $\alpha$-SMA (a marker of myofibroblast differentiation) and (b) MMP-13 staining from sham-operated mice and from the IR of MI-VEH and MI-RLX mice at 7 and 30 days post-MI, respectively. Also shown is the mean \pm s.e. (a) $\alpha$-SMA and (b) MMP-13 density (expressed as a percentage per field) from eight fields representing the NIR, BR, and IR, from the upper mid-zone, lower mid-zone, and apex of the heart of sham, $\mathrm{MI}+\mathrm{VEH}$ and $\mathrm{MI}+\mathrm{RLX}$ animals ( $n=9-12 /$ group), at 7 and 30 days post-MI. ${ }^{*} P<0.05,{ }^{* *} P<0.01,{ }^{* * *} P<0.001$ vs respective sham-operated group; ${ }^{\#} P<0.05,{ }^{\# \#} P<0.01$ vs respective $\mathrm{Ml}+\mathrm{VEH}$ group.

this and other studies. ${ }^{17,27,28}$ Histologically, the acute healing phase is featured by dense infiltration of inflammatory cells (mainly macrophages), differentiation of myofibroblasts (as indicated by $\alpha$-SMA expression), and collagen deposition. The chronic healing phase is characterized by formation of dense scars, cessation of inflammation, and a doubling of 
a
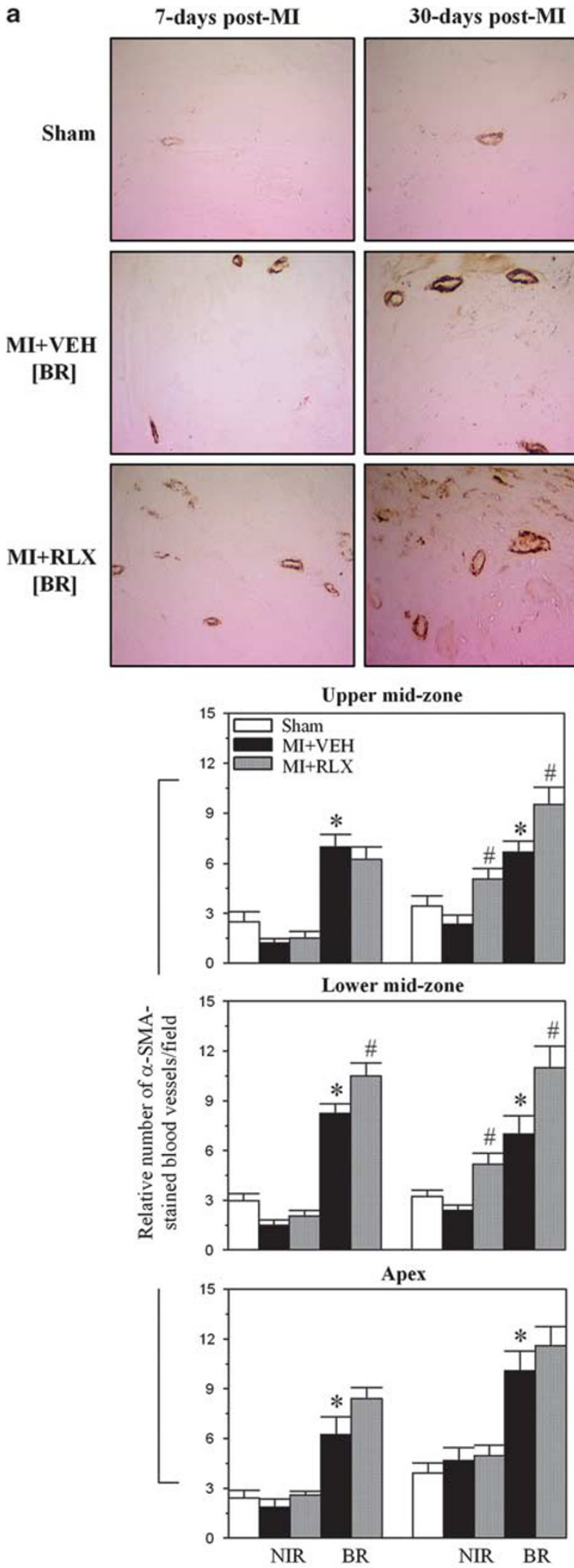

$\llcorner$ 7d post-MI $\lrcorner \quad\llcorner$ 30d post-MI $\lrcorner$ b
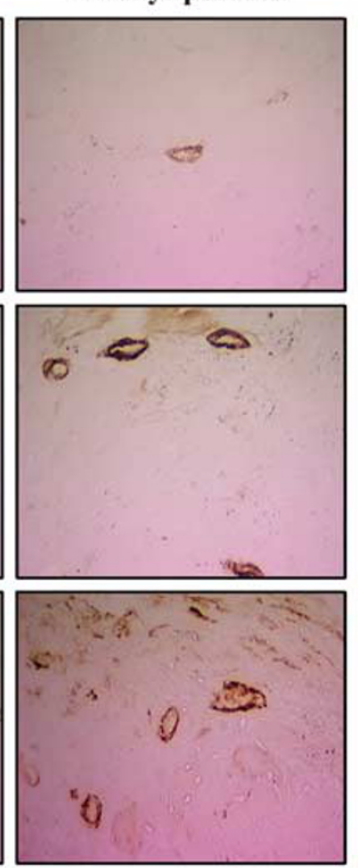

MI+RLX

[BR]
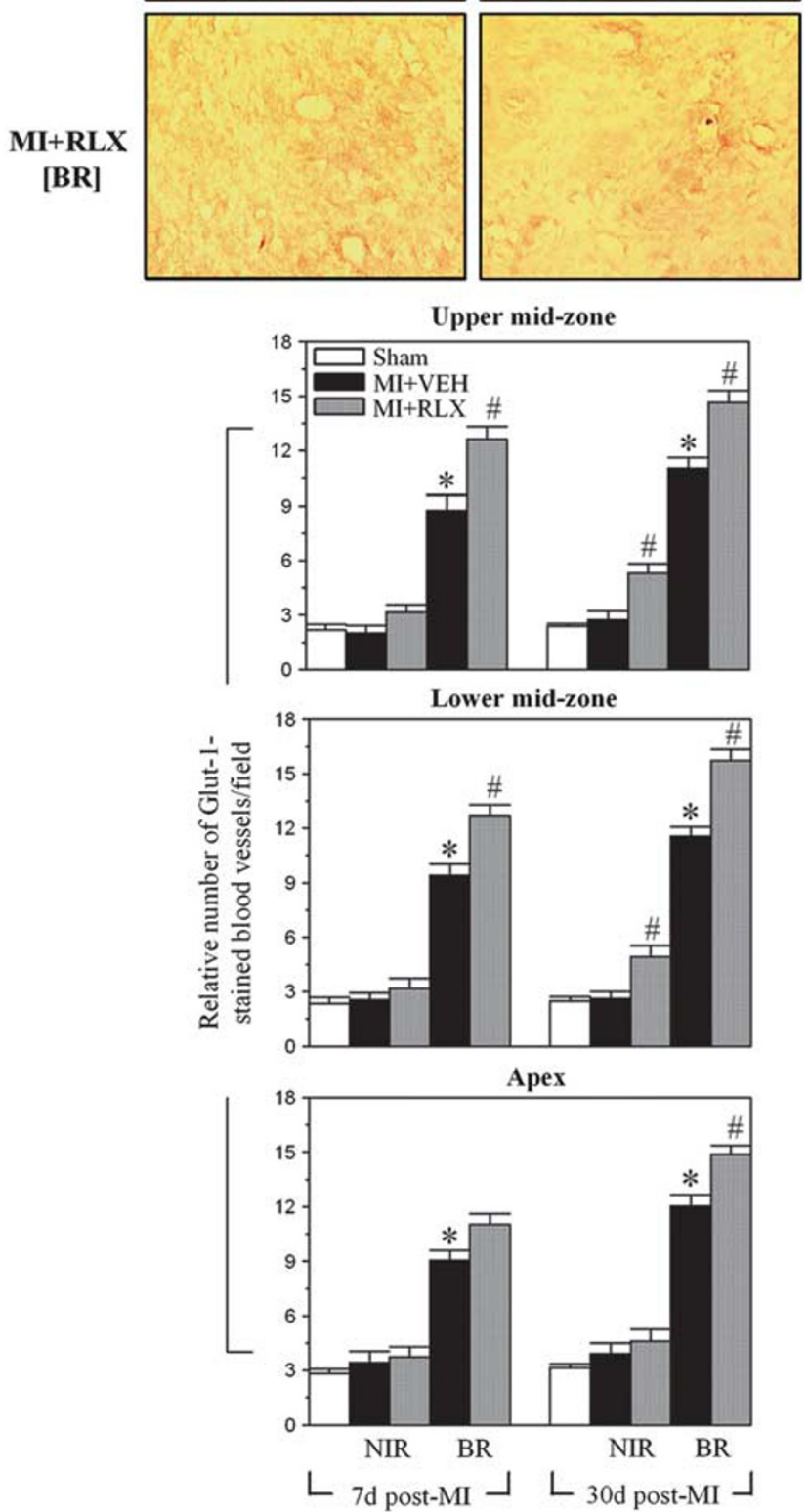

Figure 6 (a) Representative images of $\alpha$-SMA-stained blood vessels and (b) Glut-1-stained vessels from sham-operated mice, and from the NIR and $\mathrm{BR}$ of $\mathrm{MI}+\mathrm{VEH}$ and $\mathrm{MI}+\mathrm{RLX}$ mice, at 7 and 30 days post-MI. Also shown are the mean \pm s.e. blood vessel counts (from eight fields representing the $\mathrm{NIR}$ and $\mathrm{BR})$, from the upper mid-zone, lower mid-zone, and apex of the heart of sham, MI $+\mathrm{VEH}$ and $\mathrm{MI}+\mathrm{RLX}$ animals $(n=9-12 / \mathrm{group})$, at 7 and 30 days post-MI. ${ }^{*} P<0.05$ vs respective sham-operated group; ${ }^{\#} P<0.05$ vs respective $\mathrm{Ml}+\mathrm{VEH}$ group. 


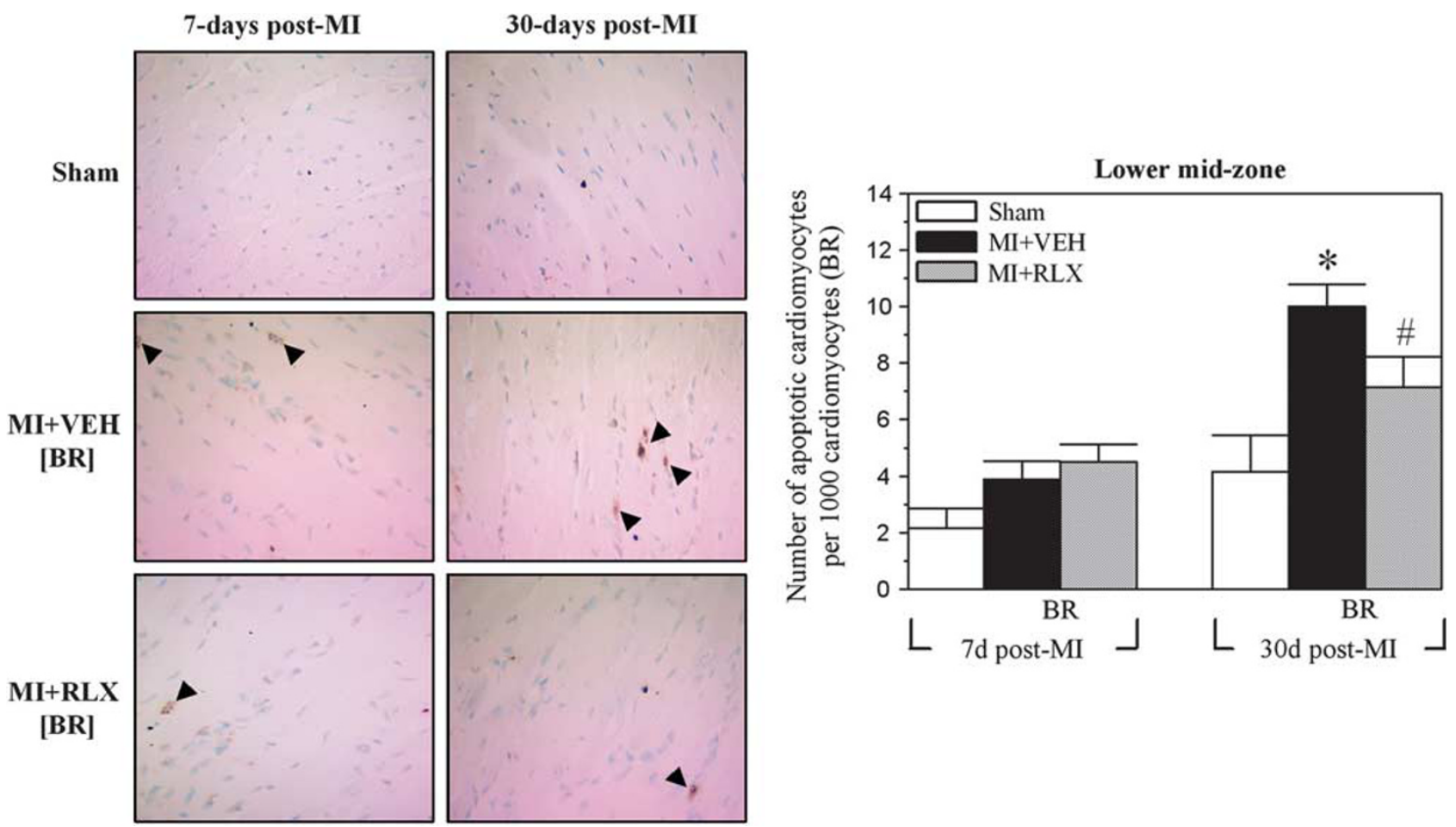

Figure 7 Representative images of TUNEL-positive-stained apoptotic cardiomyocytes from the BR of sham-operated mice, in addition to $\mathrm{MI}+\mathrm{VEH}$ and $\mathrm{MI}+\mathrm{RLX}$ mice, at 7 and 30 days post-MI. Also shown are the mean \pm s.e. apoptotic cardiomyocytes (from 1000 cardiomyocyte nuclei per BR) from the lower mid-zone of the heart of sham, MI + VEH and MI + RLX animals ( $n=9-12 /$ group), at 7 and 30 days post-MI. ${ }^{*} P<0.05$ vs respective sham-operated group; ${ }^{\#} P<0.05$ vs respective $\mathrm{Ml}+\mathrm{VEH}$ group.

vessel density together with cardiomyocyte apoptotic death at the BR.

It remains unclear if post-infarct fibrotic healing represents a therapeutic target. Earlier studies showed deleterious consequences (including a worsening of ventricular remodeling) following inhibition of fibrotic healing or the inflammatory response after infarction by means of corticosteroids. ${ }^{29,30}$ Recent research on genetically modified mice has also demonstrated the adverse consequences of impaired fibrotic healing after MI leading to aggravated ventricular rupture and remodeling, ${ }^{31,32}$ although the suppression of excessive matrix deposition is believed to be beneficial in the context of stem cell based therapies. Our findings showed that fibrotic healing post-infarction can be therapeutically remodeled by relaxin leading to a reduced density of fibrotic tissue across infarcted, non-infarcted, and border zones. Importantly, we found that the inflammatory response, estimated by the local density of macrophages in the acutely infarcted myocardium was unaltered by relaxin treatment, consistent with our previous findings in other organs. ${ }^{33}$ One novel finding in this study was a marked relaxin-induced reduction in myocardial TGF- $\beta 1$ levels across the border and infarct zones during acute and chronic MI. Myofibroblasts and to a lesser extent, cardiomyocytes and macrophages are able to produce TGF$\beta 1 .^{34}$ However, during chronic MI, the density of myofibroblasts was very low, whilst TGF- $\beta 1$ levels remained high, suggesting that other cells/cellular factors were able to maintain increasing TGF- $\beta 1$ levels in the IR. Among the various MMP subtypes present, MMP-13 is known to be constitutively expressed in the heart. ${ }^{35}$ At both time points studied, the levels of MMP-13 in the infarcted heart were consistently elevated across different regions following relaxin treatment, which is a likely contributing factor for the relaxin-mediated reduction of collagen. Hence, these findings, which are consistent with those of our previous studies, ${ }^{6,10,11,18}$ suggest that the mechanisms associated with relaxin's ability to alter post-infarct fibrotic healing involve its ability to (i) suppress the expression and influence of profibrotic factors (such as TGF- $\beta 1$ ), that promote fibrogenesis; (ii) inhibit myofibroblast differentiation and hence, myofibroblast-induced collagen synthesis; and (iii) augment MMP13-induced collagen breakdown; with these combined actions favoring a net reduction in aberrant collagen content.

The relaxin-induced remodeling of scar healing in this model are also consistent with its anti-fibrotic effects demonstrated in larger experimental models, ${ }^{14}$ and with the progressive cardiac fibrosis phenotype demonstrated in ageing relaxin-deficient mice, with resultant ventricular diastolic dysfunction. $^{21}$ The anti-apoptotic effects of relaxin in the infarcted murine heart are also consistent with its effects in a porcine model of $\mathrm{MI}^{36}$ and its ability to protect cardiomyocytes from apoptosis in vitro; ${ }^{16}$ while its pro-angiogenic 
effects are in keeping with that observed in the pig model of MI. ${ }^{14}$ The rationale for Glut-1 staining was based on previous studies using endothelial expression of Glut-1 as a marker of active de novo capillary formation; where $75 \%$ of Glut-1 expression in the heart was localized to the capillary endothelium. ${ }^{23}$ The morphological assessment of its expression was used as a surrogate marker of relaxin's pro-angiogenic properties, and to supplement the $\alpha$-SMA staining of larger vessels. In this study, we were able to demonstrate that relaxin's anti-fibrotic, anti-apoptotic and pro-angiogenic actions acted in synergy during post-infarct healing without overt adverse outcomes. Interestingly, relaxin therapy did not significantly affect the extent of hypertrophy in this infarct model, which is consistent with findings in other in vitro and in vivo models. ${ }^{18,37}$

The safety of interfering with fibrotic healing in the infarcted heart also remains unknown. Ventricular rupture, a fatal complication of $\mathrm{MI},{ }^{38}$ is only experimentally seen in mice within the first week of injury. ${ }^{22,39}$ In the present study, relaxin treatment did not significantly alter the incidence of rupture compared with that in the vehicletreated group. Regarding the severity of post-MI ventricular remodeling, while collagen content was reduced across various areas of the chronically infarcted LV wall by relaxin treatment, the degree of LV remodeling was not exacerbated compared with vehicle-treated animals matched with IS.

Despite the potential benefits of relaxin therapy on the fibrotic healing process and its ability to modestly reduce estimated infarct size in animals with moderate IS and LV area (Table 2), several measures of cardiac function (ie CO, FS, etc) were not significantly influenced by hormonal therapy in this study. It should be noted, however, that the dose of relaxin used (which produces circulating relaxin levels of $20-40 \mathrm{ng} / \mathrm{ml}$; see Williams et $a l^{19}$ and Samuel et $a l^{20}$ ) significantly elevated HR, consistent with previous findings in other rodent models. ${ }^{6,18,26}$ While interfering with some functional parameters that are sensitive to rate changes, such as Tau, a higher HR in treated animals would negatively impact on the infarcted heart. Again though, the relaxininduced higher level of HR did not appear to have any deleterious effects in the diseased heart, based on the similar extent of LV remodeling and dysfunction in MI + RLX vs $\mathrm{MI}+\mathrm{VEH}$ mice, matched by IS. It is also plausible that the $30-40 \%$ lowering of collagen density in the infarcted mouse heart may not have been enough to measurably alter chamber stiffness. Interestingly, clinical studies, including a recent one conducted on patients with acute MI, ${ }^{40}$ showed that HR was not altered by relaxin treatment in patients, even at the dose of $960 \mu \mathrm{g} / \mathrm{kg} / \mathrm{day}$. This is apparently due to a much lower density of relaxin receptors in the atria of humans than that in rodents. ${ }^{41}$ Thus, relaxin's tachycardiac effects should not be a clinical concern.

The present study is a prelude to further research in determining whether relaxin is useful on its own or in com- plementing stem cell therapies to promote myocardial regeneration in the infarcted heart. While relaxin's major mode of action in the infarct model appeared to be its antifibrotic capability, its added capacity to reduce cardiomyocyte apoptosis, while promoting blood vessel growth suggests that relaxin may hold promise as an agent for the treatment of coronary artery disease including MI. Specifically, relaxin's effects seen in the infarct model might also be complementary to cell-based therapies in this setting, which is consistent with the recent findings of Bani and colleagues in pig $^{14}$ and rat $^{42}$ models of MI, demonstrating that transplanted myoblasts genetically engineered to express relaxin at the site of cell engraftment reduced post-infarct collagen density, while increasing markers of vascularization and cardiac function. Progress in cell-based therapies has been hampered by a very low viability of implanted stem cells, insufficient nourishment and fibrotic environment of the host, poor functional coupling with viable host cardiomyocytes, and incomplete differentiation. In the infarcted heart, treatment with relaxin is likely to improve the milieu thereby complementing the regeneration of cardiomyocytes from endogenous progenitor cells or engrafted myogenic stem cells. Since inflammatory cytokines and MMP activity are known to be critical for stem cell homing, migration, and differentiation, ${ }^{5}$ it is important to note that these processes were largely unaffected (macrophage infiltration) or even enhanced (MMPs) by relaxin treatment.

In conclusion, relaxin therapy significantly reduced the amount of cardiac fibrosis in various regions of the infarcted heart, at early and late phases of MI. This anti-fibrotic action was also associated with a relaxin-mediated promotion of angiogenesis and inhibition of cardiomyocyte apoptosis, particularly during chronic MI. Importantly, no adverse consequences were detected following relaxin administration. Thus, relaxin is emerging as a suitable therapy for the postinfarct heart and may be supplementary to cell-based therapies in the setting of ischemic heart disease.

\section{ACKNOWLEDGEMENTS}

We sincerely thank Dr Tim Hewitson (Department of Nephrology, Royal Melbourne Hospital, Parkville, Victoria, Australia) and Dr Siew Yeen Chai (Howard Florey Institute) for providing the $f 4 / 80$ and Glut-1 antibodies, respectively. This study was supported in part by an Australian Stem Cell Centre Project Grant to Chrishan S Samuel, Ross AD Bathgate, and Xiao-Jun Du; a National Heart Foundation of Australia/National Health and Medical Research Council of Australia (NHMRC) R D Wright Fellowship to Chrishan S Samuel, NHMRC Senior Research Fellowships to Geoffrey W Tregear, Ross AD Bathgate, and Xiao-Jun Du, and by the Victorian Government's

Operational Infrastructure Support Program.

\section{DISCLOSURE/CONFLICT OF INTEREST}

The authors declare no conflict of interest.

1. See F, Kompa A, Martin J, et al. Fibrosis as a therapeutic target postmyocardial infarction. Curr Pharm Des 2005;11:477-487.

2. Jugdutt BI. Remodeling of the myocardium and potential targets in the collagen degradation and synthesis pathways. Curr Drug Targets Cardiovasc Haematol Disord 2003;3:1-30. 
3. Braunwald E, Bristow MR. Congestive heart failure: fifty years of progress. Circulation 2000;102:IV14-IV23.

4. Sun Y, Weber KT. Infarct scar: a dynamic tissue. Cardiovasc Res 2000;46:250-256.

5. Lu L, Zhang JQ, Ramires FJ, et al. Molecular and cellular events at the site of myocardial infarction: from the perspective of rebuilding myocardial tissue. Biochem Biophys Res Commun 2004; 320:907-913.

6. Samuel CS, Du XJ, Bathgate RAD, et al. Relaxin the stiffened heart and arteries: the therapeutic potential for relaxin in the treatment of cardiovascular disease. Pharmacol Therap 2006;112:529-552.

7. Dschietzig T, Bartsch C, Baumann G, et al. Relaxin-a pleiotropic hormone and its emerging role for experimental and clinical therapeutics. Pharmacol Therap 2006;112:38-56.

8. Nistri S, Bigazzi M, Bani D. Relaxin as a cardiovascular hormone: physiology, pathophysiology and therapeutic promises. Cardiovasc Hematol Agents Med Chem 2007;5:101-108.

9. Sherwood OD. Relaxin's physiological roles and other diverse actions. Endocr Rev 2004;25:205-234.

10. Samuel CS, Hewitson TD, Zhang Y, et al. Relaxin ameliorates fibrosis in experimental diabetic cardiomyopathy. Endocrinology 2008;149: 3286-3293.

11. Samuel CS, Unemori EN, Mookerjee I, et al. Relaxin modulates cardiac fibroblast proliferation, differentiation and collagen production and reverses cardiac fibrosis in vivo. Endocrinology 2004;145: 4125-4133.

12. Mookerjee I, Hewitson TD, Halls $\mathrm{ML}$, et al. Relaxin inhibits renal myofibroblast differentiation via RXFP1, the nitric oxide pathway, and Smad2. FASEB J 2009:23:1219-1229.

13. Dschietzig T, Stangl K. Relaxin: a pregnancy hormone as central player of body fluid and circulation homeostasis. Cell Mol Life Sci 2003;60:688-700.

14. Formigli L, Perna AM, Meacci $E$, et al. Paracrine effects of transplanted myoblasts and relaxin on post-infarction heart remodelling. J Cell Mol Med 2007;11:1087-1100.

15. Unemori EN, Lewis $M$, Constant J, et al. Relaxin induces vascular endothelial growth factor expression and angiogenesis selectively at wound sites. Wound Repair Regen 2000;8:361-370.

16. Moore XL, Tan SL, Lo CY, et al. Relaxin antagonizes hypertrophy and apoptosis in neonatal rat cardiomyocytes. Endocrinology 2007;148: 1582-1589.

17. Gao XM, Dart AM, Dewar E, et al. Serial echocardiographic assessment of left ventricular dimensions and function after myocardial infarction in mice. Cardiovasc Res 2000:45:330-338.

18. Lekgabe ED, Kiriazis $H$, Zhao $C$, et al. Relaxin reverses cardiac and renal fibrosis in spontaneously hypertensive rats. Hypertension 2005;46: 412-418.

19. Williams EJ, Benyon RC, Trim N, et al. Relaxin inhibits effective collagen deposition by cultured hepatic stellate cells and decreases rat liver fibrosis in vivo. Gut 2001;49:577-583.

20. Samuel CS, Zhao C, Bathgate RA, et al. Relaxin deficiency in mice is associated with an age-related progression of pulmonary fibrosis. FASEB J 2003;17:121-123.

21. Du XJ, Samuel CS, Gao XM, et al. Increased myocardial collagen and ventricular diastolic dysfunction in relaxin deficient mice: a genderspecific phenotype. Cardiovasc Res 2003;57:395-404.

22. Gao XM, Xu Q Kiriazis $\mathrm{H}$, et al. Mouse model of post-infarct ventricular rupture: time course, strain- and gender-dependency, tensile strength, and histopathology. Cardiovasc Res 2005;65: 469-477.
23. Davey KA, Garlick PB, Warley A, et al. Immunogold labeling study of the distribution of GLUT-1 and GLUT-4 in cardiac tissue following stimulation by insulin or ischemia. Am J Physiol Heart Circ Physiol 2007;292:H2009-H2019.

24. Gao XM, Agrotis A, Autelitano DJ, et al. Sex hormones and cardiomyopathic phenotype induced by cardiac beta 2-adrenergic receptor overexpression. Endocrinology 2003;144:4097-4105.

25. Xu Q, Dalic A, Fang L, et al. Myocardial oxidative stress contributes to transgenic beta(2)-adrenoceptor activation-induced cardiomyopathy and heart failure. Br J Pharmacol 2 October 2010, e-pub ahead of print.

26. Kakouris H, Eddie LW, Summers RJ. Cardiac effects of relaxin in rats. Lancet 1992;339:1076-1078.

27. Du XJ, Gao XM, Kiriazis $\mathrm{H}$, et al. Transgenic alpha1A-adrenergic activation limits post-infarct ventricular remodeling and dysfunction and improves survival. Cardiovasc Res 2006;71:735-743.

28. Yang $F$, Liu $\mathrm{YH}$, Yang $\mathrm{XP}$, et al. Myocardial infarction and cardiac remodelling in mice. Exp Physiol 2002;87:547-555.

29. Sholter DE, Armstrong PW. Adverse effects of corticosteroids on the cardiovascular system. Can J Cardiol 2000;16:505-511.

30. Hwang MW, Matsumori A, Furukawa $\mathrm{Y}$, et al. Neutralization of interleukin-1beta in the acute phase of myocardial infarction promotes the progression of left ventricular remodeling. J Am Coll Cardiol 2001;38:1546-1553.

31. Nahrendorf M, Hu K, Frantz $\mathrm{S}$, et al. Factor XIII deficiency causes cardiac rupture, impairs wound healing, and aggravates cardiac remodeling in mice with myocardial infarction. Circulation 2006;113:1196-1202.

32. Heymans $S$, Luttun $A$, Nuyens $D$, et al. Inhibition of plasminogen activators or matrix metalloproteinases prevents cardiac rupture but impairs therapeutic angiogenesis and causes cardiac failure. Nat Med 1999;5:1135-1142.

33. Royce SG, Miao YR, Lee M, et al. Relaxin reverses airway remodeling and airway dysfunction in allergic airways disease. Endocrinology 2009:150:2692-2699.

34. Khan R, Sheppard R. Fibrosis in heart disease: understanding the role of transforming growth factor-beta in cardiomyopathy, valvular disease and arrhythmia. Immunology 2006;118:10-24.

35. Peterson JT, Li H, Dillon L, et al. Evolution of matrix metalloprotease and tissue inhibitor expression during heart failure progression in the infarcted rat. Cardiovasc Res 2000;46:307-315.

36. Perna AM, Masini E, Nistri $\mathrm{S}$, et al. Novel drug development opportunity for relaxin in acute myocardial infarction: evidences from a swine model. FASEB J 2005;19:1525-1527.

37. Xu Q, Lekgabe ED, Gao XM, et al. Endogenous relaxin does not affect chronic pressure overload-induced cardiac hypertrophy and fibrosis. Endocrinology 2008;149:476-482.

38. Reardon $\mathrm{MJ}$, Carr $\mathrm{CL}$, Diamond $\mathrm{A}$, et al. Ischemic left ventricular free wall rupture: prediction, diagnosis, and treatment. Ann Thorac Surg 1997:64:1509-1513.

39. Fang $\mathrm{L}, \mathrm{Gao} X \mathrm{M}$, Moore $\mathrm{XL}$, et al. Differences in inflammation, MMP activation and collagen damage account for gender difference in murine cardiac rupture following myocardial infarction. J Mol Cell Cardiol 2007;43:535-544.

40. Dschietzig $\mathrm{T}$, Unemori $\mathrm{E}$, Wood $\mathrm{S}$, et al. A pilot safety and dose-finding trial of intravenous recombinant relaxin in compensated congestive heart failure. Eur Heart J 2007;28(Suppl):387.

41. Osheroff PL, Cronin MJ, Lofgren JA. Relaxin binding in the rat heart atrium. Proc Natl Acad Sci USA 1992;89:2384-2388.

42. Bonacchi M, Nistri S, Nanni C, et al. Functional and histopathological improvement of the post-infarcted rat heart upon myoblast cell grafting and relaxin therapy. J Cell Mol Med 2009;13:3437-3448. 